\title{
Formación de docentes y modelo pedagógico en la Universidad Pedagógica y Tecnológica de Colombia
}

\author{
Teachers training and pedagogical model at the Universidad Pedagógica y \\ Tecnológica de Colombia
}

Formação de docentes e o modelo pedagógico da Universidade Pedagógica e Tecnológica da Colômbia

\author{
Diana Elvira Soto Arango ${ }^{1}$ \\ Universidad Pedagógica y Tecnológica de Colombia (Colombia) \\ Grupo de investigación HISULA \\ José Pascual Mora García ${ }^{2}$ \\ Universidad de Los Andes- Táchira (Venezuela) \\ Grupo de investigación HISULA \\ José Rubens Lima Jardilino ${ }^{3}$ \\ Universidad Federal de Ouro Preto (Brasil) \\ Grupo de investigación HISULA
}

Recepción: 13/07/2017

Evaluación: 04/08/2017

Aceptación: 24/08/2017

Artículo de Investigación - Reflexión

DOI: https://doi.org/10.19053/01227238.7552

1 Decana de la Facultad de Ciencias de la Educación y Profesora Titular de la Universidad Pedagógica y Tecnológica de Colombia, Codirectora de los Grupos de Investigación: HISULA, ILAC y editora de la Revista Historia de la Educación Latinoamericana. ORCID: 0000-0002-3821-7550. Clasificada en sénior en COLCIENCIAS, 2017. Email: dianaelvorasoto@gmail.com

2 Profesor titular Emérito de la Universidad de Los Andes- Táchira. Investigador del Grupo HISULA UPTC. Presidente de la red de historiadores SHELA (2011-2016) Profesor Doctorado Ciencias de la Educación, CADE-UPTC-Universidad Pedagógica y Tecnológica de Colombia. Email: pascualmoraster@gmail.com

3 Docente investigador de la Universidad Federal de Ouro Preto, Minas Gerais, Brasil, director del Grupo de Investigación Formación y Profesión Docente (FOPROFI) co-director del Grupos HISULA.UPTC, Profesor Doctorado Ciencias de la Educación, CADEUPTC-Universidad Pedagógica y Tecnológica de Colombia, Editor de la Revista Brasileira de Pesquisa sobre Formação de Professores - RBPFP. ORCID:0000-0003-2394-9465. Email: rjardilino@gmail.com 


\section{RESUMEN ${ }^{4}$}

El modelo pedagógico de la Facultad de Ciencias de la Educación de la Universidad Pedagógica y Tecnológica de Colombia se concibe a partir del enfoque humanístico, propuesto por la Universidad desde sus inicios con el antecedente directo de la Escuela Normal Superior en Colombia. La aproximación al enfoque educativo y a los modelos pedagógicos que subyacen en la facultad se establece desde el método de la historia social de la educación, los imaginarios, y el análisis cualitativo. Se concluye que el enfoque educativo humanístico cambió de católico a crítico y se mantiene bajo el principio de la integralidad del ser humano, se evidencia una aproximación a la tendencia cognoscitiva actual, que se ubica en la escuela del pensamiento epistemológico y se inclina hacia modelos críticos sociales dentro de un código ético de principios, enmarcados en la identidad del desempeño profesional del educador. Se propone, en la aproximación al modelo pedagógico crítico, una tríada equilibrada en la cual se llega desde el educador y el educando al centro focal del acto del conocimiento, esto bajo el principio de la dialogicidad y mediado por la responsabilidad social, la pedagogía emancipatoria y la felicidad del ser humano en la construcción de la paz de Colombia.

Palabras clave: educación; Escuela modelo pedagógico; humanismo; responsabilidad social.

\section{ABSTRACT}

The pedagogical model of The Science Education Faculty is conceived at the Universidad Pedagógica y Tecnológica de Colombia on the humanistic approach, proposed since its inception with the direct antecedent of the Teacher college, originally named; Superior Normal School, in Colombia. The focus on the educational approach and the pedagogical models that underlie the faculty are established from the social history of education method, the imaginaries, and the qualitative analysis. It is concluded that the humanistic educational approach changed from Catholic to critical and keeps the principle of the integrality of the human being. An approximation to the current cognitive trend, located in the school of epistemological thought and leaned towards socio-critical models within an ethical code of principles, which are framed in the identity of the professional performance of the educator. It is proposed, in the approach to the critical pedagogical model, a balanced triad where the educator and the learner reach the focal point in the act of knowledge, this under the principle of dialogicity and mediated by social responsibility, emancipatory pedagogy and the happiness of the human being in the construction of peace in Colombia.

Keywords: education; pedagogical model pedagogy; humanism; social responsibility.

\section{RESUMO}

O modelo pedagógico da Faculdade de Ciências da Educação da Universidade Pedagógica e Tecnológica da Colômbia é concebido a partir do enfoque humanístico, proposto pela universidade desde seu início, com o antecedente direto da Escola Normal Superior na Colômbia. A abordagem do enfoque educativo e dos modelos pedagógicos subjacentes na faculdade foi estabelecida a partir do método da história social da educação, dos imaginários e da análise qualitativa. Conclui-se que o enfoque educativo humanístico mudou do católico ao crítico e se mantém sob o

\footnotetext{
4 Se agradece a profesores a miembros del Consejo de la Facultad de Educación, a la Comisión dinamizadora y las líneas de investigación de la Facultad por el marco histórico y actual. Se agradece la revisión dada a este trabajo por parte del Dr. Antonio Galvis y revisión de citas por Carolina Pulido.
} 
princípio da integridade do ser humano; é evidente uma aproximação à tendência cognoscitiva atual, que é embasada na escola do pensamento epistemológico e se inclina na direção de modelos críticos sociais dentro de um código ético de princípios, fundamentados na identidade do desempenho profissional do educador. Propõe-se, na aproximação ao modelo pedagógico crítico, uma tríade equilibrada por meio da qual se chega, a partir do educador e do educando, ao centro focal do ato do conhecimento, isto sob o princípio da dialogicidade e mediado pela responsabilidade social, à pedagogia emancipatória e a felicidade do ser humano na construção da paz da Colômbia.

Palavras-chave: Educação; Escola Nova; pedagogia; humanismo; responsabilidade social.

Contextualización: idioma Maya K'iche' Contextualizador: Manuel Ricardo Ixmatá Tahay Ministerio de Educación de Guatemala

\section{CH'UTIN TZIJ}

Ub'antajik ri choltijonik rech ri unimal tijonik pa Colombia, kakichomaj chi ruk' ri ub'e'al uwinaqil, ya'om ub'ixik rumal ri unimal tijonik ojer taq tzij majitajnaq la rumal ri nima tijob'al Colombia.

Rilik ri ub'e'al tijonik xuquje' ub'antajik ri choltijonik kariqitaj ruk' choleta'mab'al k'ulmatajem tijonik, ri rayib'al $k^{\prime} u^{\prime} x$, xuquje' ri rutzil unik'oxik. Kuk'isb'ej uch'ob'ik ri ub'e'al uwinaqil xuk'ex utyoxil ruk' uq'alajsaxik ri chomanik chi ri winaq xa jun ub'antajik, kaq'alajinik chi xuk'am ri no'jib'al rech taq we q'ij kamik, kariqitaj pa ri tijob'al uxe'al chomanik kuya uchoq'ab' ri uch'ob'ik uq'aljsaxik ruk' jun suk' k'aslemal, rech ri uchak upatan ri ajtij. Kuqxa'nix ub'antajik choltijonik kuq'aljsaj ruk' oxib' ub'antajik: ajtij, tijoxel xuquje' eta'mab'al, kab'antaj ruk' ri tzijonem xuquje' jik uq'axexik, ri k'extajem choltijonik ruk' ri ki'kotemal ri winaq rech uwokik ri jamaril pa Colombia.

Uk'u'x taq tzij: tijonik; $k^{\prime} a k^{\prime}$ a tijob'al; choltijonik; winaqil; jik uq'axexik

\section{INTRODUCCIÓN}

Lainvestigación ${ }^{5}$,seplanteadesdeel proyectodeinvestigaciónquedesarrollamos sobre Escuelas Normales. De esta manera, la pregunta se orienta hacia ¿Cuál es la pertinencia e incidencia del enfoque sobre la educación y de los modelos pedagógicos que han circulado en la facultad, con las transformaciones que se han generado en la UPTC, desde el compromiso institucional y acompañamiento en la formación de educadores, que presentan impacto visible en nuestra sociedad multicultural, que se proyecta en unos imaginarios, con sueños colectivos, dentro del siglo XXI? Por ende, la pregunta se ubica en un contexto histórico-político de la Facultad de Educación en el enfoque y modelos pedagógicos. Desde allí, los

$5 \quad$ Este trabajo se elaboró expresamente para aportar a la revisión del modelo pedagógico de la Facultad de Ciencias de la Educación y de la Universidad Pedagógica y Tecnológica de Colombia, desde el grupo de investigación Historia y Prospectiva de la Universidad Latinoamericana. HISULA con el proyecto de investigación Formación de educadores en las escuelas normales superiores. Convenio UPTC. 2010-2017. SGI. 2192 Dirección de Investigaciones Universidad Pedagógica y Tecnológica de Colombia. Lidera Dra. Diana Elvira Soto Arango Presentado en Consejo de Facultad de Ciencias de la Educación el día 17 de mayo de 2017. 
planes de desarrollo nacional e institucional los contrastamos para establecer unos lineamientos sobre los mismos, acorde a las transformaciones institucionales, locales-multiculturales, que se han generado en esta Universidad, formadora de educadores y que se proyecta con utopías dentro de los imaginarios colectivos de la comunidad universitaria.

Por lo tanto, se justificó el estudio para destacar la reflexión educativapedagógica- política, sobre el origen, desarrollo y proyección de la universidad, desde la Escuela Normal Superior, hasta llegar a la institución multiprofesional que ha respondido significativamente, a las necesidades educativas de la región y el país, en contextos históricamente multiculturales. Por otra parte, por los retos y desafíos en la sociedad actual colombiana, en procesos de paz, que hace necesario trazar estrategias de formación con nuevos modelos pedagógicos, que contribuyan desde la equidad, como un derecho para el aseguramiento del bien público, en el establecimiento del Estado Nacional.

La comprensión del Postconflicto como la superación de la violencia estructural requiere de una repedagogización de los engramas cognitivos y la construcción de "andamios mentales" (Febvre) resilientes, el desarrollo de paz emancipatoria en las comunidades vulnerables. La violencia estructural interiorizada en las múltiples guerras desde el siglo XIX, y en particular desde la guerra de los mil días, y los recientes Acuerdos de Paz firmados entre el Estado y las FARC 6 requieren de generar procesos de repedagogización para la consolidación de una paz sostenible.

Los emergentes modelos pedagógicos de la UPTC deben incorporar la cultura de la paz como su acicate central ${ }^{7}$. En tal sentido, planteamos ¿Cuál es el contenido y la metodología de la emergente pedagogía y didáctica de la paz?, ¿En qué consiste una cultura de la paz en etapa del postacuerdo? Porque históricamente las pedagogías de la obediencia ${ }^{8}$ legitimaron el estatus que de la dominación y la exclusión. La pedagogía que sirvió para la enajenación de las conciencias y la defensa de los privilegios asociados a la propiedad rural debe ser revisada; la pedagogía que legitimó la casta política proclive a la violencia debe ser superada; la pedagogía de la resignación amparada en dogmas religiosos debe ser modificada; necesitamos de una pedagogía contrahegemónica que emancipe las conciencias en la construcción de una paz y DDHH sostenibles.

Asimismo, se hace necesario analizar la prospectiva de la Facultad y de la UPTC, desde un estudio participativo con los principios, criterios y estrategias de procesos de mejora, en las condiciones de calidad de la formación investigativa en la práctica pedagógica, que atiende este nivel de formación educativo, dentro de unos imaginarios y sueños colectivos hacia el siglo XXI.

El trabajo se presenta en tres apartados. En primera instancia se establece como objetivo central, el analizar la conceptualización sobre la política pública, reformas y ética en educación para luego estudiar los enfoques educativos y modelos

6 FARC: Fuerzas Armadas Revolucionarias de Colombia.

7 Inspiradas en la Ley 1732, del 1 de septiembre de 2014, "por la cual se establece la cátedra de la paz en todas las instituciones educativas del país".

8 "La Educación Prohibida", https://www.youtube.com/watch?v=-1Y9OqSJKCc, recoge la crítica a los paradigmas centrados en las pedagogías tradicionales, de la cual Paulo Freire ha sido pionero con la pedagogía del oprimido. 
pedagógicos que han circulado en la facultad de ciencias de la educación de la UPTC, del siglo XX al XXI. y finalmente hacer un acercamiento de aproximación a un modelo pedagógico.

Se estableció el análisis de este trabajo desde el método que se centró en la historia social de la educación ${ }^{9}$, incursionando en las mentalidades con los imaginarios ${ }^{10}$, sueños colectivos y la investigación cualitativa. De esta manera, la revisión teórica se sustenta en resultados de proyectos de investigación, y la propuesta final asimila, recoge y sintetiza los documentos elaborados y sustentados en un trabajo colectivo de asambleas, grupos, análisis de los proyectos académicos de cada programa y las líneas de investigación que fueron revisadas y aprobadas por el Consejo de la Facultad de Educación en marzo de 2017. Nos interesa destacar cómo se construyó y qué se viene aportando en elementos teóricos, metodológicos y estratégicos, para pensar en una «nueva perspectiva» de un enfoque educativo y modelo pedagógico en la Facultad de Educación. Es así, que desde una realidad concreta y con el acompañamiento de teóricos clásicos y modernos de la educación y la pedagogía, intentamos renovar las categorías y principios educativos-pedagógicos, tratando de incorporar nuestros temas locales y a su vez inmersos en los contextos latinoamericanos.

En general, se concluye que se mantiene el enfoque educativo humanístico, pero con un cambio del católico al crítico, bajo el principio de la integralidad del ser humano y se da una aproximación a la tendencia actual cognoscitiva, que se enmarca en la escuela del pensamiento epistemológico, que se inclina a modelos críticos sociales. Asimismo, desde la tradición histórica de la relevancia en cada momento del educador o el educando o medios, se contrapone la aproximación a un modelo pedagógico que se plantea desde una tríada, en un mismo plano de relevancia, donde al centro focal del acto del conocimiento se llega desde el educador y el educando, mediado por los principios de la ética, la integralidad, la responsabilidad social y hacia la felicidad del ser humano.

\section{Política Pública, Reformas y Ética en Educación}

La educación y la ética son inherentes a toda sociedad. Sin embargo, se asimilan de manera diferente, según los contextos históricos-socio-políticosculturales ${ }^{11}$. Para el caso colombiano partimos de la pregunta del proyecto de Vendimia, respecto a ¿Qué relación han tenido las culturas políticas, las formas de mestizaje cultural en las regiones, los proyectos de nación y las instituciones educativas colombianas, con los problemas de gobernabilidad y legitimidad, que

9 Se toma de base lo indicado en José Pascual Mora García, Diana Soto Arango y José Rubens Lima Jardilino, "La historia de la educación en América Latina: Contribución y aportes de la Sociedad de Historia de la Educación Latinoamericana SHELA (19942015)" Revista História da Educação No. 51, Vol. 21 (2017): 351- 375. http://seer.ufrgs.br/index.php/asphe/issue/view/2822/ showToc.

10 Bronislaw Baczko. Los imaginarios sociales. Memorias y esperanzas colectivas (Buenos Aires, Ediciones nueva Visión, 1991. Primera versión París 1984), 8.

11 Comprende todos aquellos aspectos desde el punto de vista material y mental que ha construido el hombre para determinar su existencia. La cultura comprende elementos como: creencias, normas, costumbres, usos, artefactos, el lenguaje, elementos simbólicos, el arte. Es decir, todo aquello que no es producido por la naturaleza. La cultura se aprende, se comparte, se crea. 
existen en las relaciones entre gobernantes y gobernados, entre instituciones, grupos civiles y expresiones de oposición en la Colombia actual? ${ }^{12}$

Es así, que, para poder establecer la relación de educación y ética en la UPTC desde la política pública ${ }^{13}$ debemos clarificar en primera instancia los conceptos básicos de: política pública, reforma educativa, enfoque educativo, modelo pedagógico, ética e integridad profesional.

En este sentido, entendemos la política pública, como los fines e intenciones que presenta el Estado ${ }^{14}$, en un período determinado de gobierno, como grupo de poder que identifica problemas y establece metas para alcanzar desde su visión política, económica, cultural y educativa unos propósitos de transformación. Es decir, "una política pública existe siempre y cuando instituciones estatales asuman total o parcialmente la tarea de alcanzar objetivos estimados como deseables o necesarios, por medio de un proceso destinado a cambiar un estado de cosas percibido como problemático" ${ }^{15}$. Entendemos que la política pública supera un ciclo de decisión, siendo el "lugar donde una sociedad dada construye su relación con el mundo"16. En Colombia, el Ministerio de Educación Nacional conceptualiza la política pública de educación superior como: "los lineamientos a seguir, que el país define con relación a la educación superior, que requiere y necesita, para el mediano y largo plazo, de modo que sea coherente con su visión de desarrollo y bienestar social" ${ }^{\prime 17}$. Por otra parte, la política pública se concreta en actos legislativos y normatiza las prácticas administrativas, financieras y académicas de la institución ${ }^{18}$.

Las reformas educativas, las concebimos desde la política pública que expresa el pensamiento político-filosófico-cultural, enmarcado en los valores que tenga el gobierno referente a la educación, la pedagogía, los educadores, los educandos y la relevancia que se le da a la educación en el país, en la construcción de un sujeto social, comprometido con su contexto y responsable de ser ciudadano. Cabe anotar que detrás de una reforma educativa se localiza un grupo político. Por lo tanto, es relevante conocer en primer lugar: ¿qué tipo de filosofía e influencia externa asimilaron?, ¿cuál fue la predominante? y ¿qué características particulares asumió la formación de los educadores en el adaptacionismo de las políticas públicas de reforma propuestas? Segundo, la reforma se cristaliza en la legislación, con el proyecto de la política pública del Estado, que normatiza la

12 Proyecto liderado por HISULA y presentado a COLCIENCIAS en el año 2006.

13 El Ministerio de Educación Nacional en Colombia conceptualiza la política pública de Educación Superior como "los lineamientos a seguir que el país define con relación a la educación superior que requiere y necesita, para el mediano y largo plazo, de modo que sea coherente con su visión de desarrollo y bienestar social". CESU. "Construyendo una política pública de educación superior", en Boletín del Consejo Nacional de Educación Superior-CESU. 2013, p. 1.

14 El Estado "es percibido como reflejo de la voluntad general". La nación es la organización social, que se da donde la mayoría de la población en un Estado moderno configura una unidad social claramente reconocible, que se aproxima al tipo ideal de sociedad" en Hans-Joachin Koning, En el camino hacia la nación. Nacionalismo en el proceso de formación del Estado y de la Nación de la Nueva Granada, 1750-1856 (Bogotá: Banco de la República, 1994), p. 35.

15 André-Noël Roth Deubel, Políticas públicas. Formulación, implementación y evaluación. (Bogotá: Ediciones Aurora 2002), p. 27.

16 Pierre Müller, Les politiques publiques, Coll. ¿Que sais-je? (Paris: 6e édition, PUF, 2015).

17 Consejo Nacional de Educación Superior. CESU. “Construyendo una política pública de educación superior” Boletín del Consejo Nacional de Educación Superior No. 1 (2015).

18 Véase un estudio sobre la metodología para estudiar una reforma universitaria en Diana Elvira Soto Arango, La reforma del Plan de Estudios del fiscal Moreno y Escandón. 1774-1779 (Bogotá: Centro Editorial Universidad del Rosario, 2004), 2-3. 
formación del educador en la institución educativa (escuelas normales, institutos pedagógicos y universidades).

De esta manera, podríamos decir que: "en el siglo XX, cuando el sistema educativo está ya configurado y la educación es un derecho fundamental, que impone obligaciones y deberes al Estado y a los ciudadanos, surge el campo de la política pública y una reflexión más sistemática sobre las tendencias del desarrollo del sistema educativo, el funcionamiento de las instituciones escolares y los procesos de transformación y cambio en los dos niveles"19. En este sentido, el contenido del derecho a la educación y las obligaciones del Estado en el siglo XXI, se derivan además, de un marco normativo integrado por los instrumentos internacionales de Derechos Humanos, ratificados por Colombia, las observaciones de la Relatoría Especial de las Naciones Unidas para el Derecho a la Educación, la Constitución Política de Colombia de 1991 y la jurisprudencia de la Corte Constitucional ${ }^{20}$.

En este aspecto, debemos señalar que las reformas educativas no son lineales. Por supuesto, el acto del conocimiento que se estructura desde la política pública, reformas y normativas institucionales, no se construye mecánicamente. Si bien es cierto que toda sociedad establece los mecanismos para formar el ideal de ciudadano y encontramos que la educación es el primer baluarte, que centraliza la política de este acto de conocimiento. Pero, se debe tener en cuenta, que el proceso que nos lleva a esta construcción se da por la relación del educador y el educando y mediado por una sociedad que presenta, en la actualidad, referentes más fuertes y que inciden en el acto de conocimiento como son los medios de comunicación ${ }^{21}$.

Debemos partir de nuestro contexto histórico, con la prospectiva trazada en la universidad hacia el 2026. Porque la educación no se da en el vacío, por el contrario, si la entendemos como lo indica el educador brasileño Paulo Freire $(1921-1997)^{22}$, es un acto del conocimiento realizado en un tiempo y espacio históricos, que evidencia acciones políticas en esa tríada que se establece con el educador y el educando, inmersos en contextos de la responsabilidad social. Este conoce, interrelaciona los referentes éticos-culturales, que se sustentan en unos valores sociales heredados, pero que están en el hoy, en continua transformación.

En tal sentido, ubicándonos desde la Facultad de Educación de la UPTC, en el año 2017, con la responsabilidad de formar educadores para los diferentes niveles educativos en Colombia y para esta generación ubicada en lo global, se tiene la doble responsabilidad de construir el acto del conocimiento bajo las prácticas de los valores y los sueños anhelados, que traen los educandos, con los posibles que desean poner en práctica los educadores y los valores éticos que les presenta la institución universitaria, en su enfoque educativo y modelo pedagógico.

19 Aura Puyana y Mariana Serrano. Reforma o inercia en la universidad latinoamericana. La Universidad Nacional de Colombia y la Universidad Nacional Autónoma de México (Bogotá: Tercer Mundo, Universidad Nacional de Colombia e IEPRI, 2000), pp. 18 y 25.

20 Programa de Seguimiento y Evaluación de Políticas Públicas en Derechos Humanos - PROSEDHER-, Sistema de Seguimiento y Evaluación de la Política Pública Educativa a la Luz del Derecho a la Educación (Bogotá: 2004), p. 4.

21 Véase ente otros estudios Diana Elvira Soto Arango, Sandra Bernal y otros. La independencia americana. Textos, enseñanza e imaginarios escolares en Colombia y España. (Tunja, Universidad Pedagógica y Tecnológica de Colombia, 2017), pp. 57-86.

22 Véase la Revista Historia de la Educación Latinoamericana. No.10, 2008 con estudio monográfico sobre el educador Paulo Freire. 
En la Facultad de Educación, desde sus inicios, el enfoque ${ }^{23}$ educativo se ha centrado en el humanismo, especialmente el católico ${ }^{24}$, pero se ha dado un cambio desde finales del siglo XX y comienzos del XXI en la construcción de un humanismo crítico $^{25}$, sustentado en estrategias de varias escuelas y modelos pedagógicos. Para el siglo XXI, nuestro enfoque en la concepción de la educación ${ }^{26}$ lo concebimos como el proceso formativo, humanístico-crítico- dialógicoincluyente, construido desde la singularidad histórica de la cultura política, con responsabilidad social, sustentado en el principio de la integralidad del ser humano ${ }^{27}$, que se desarrolla, en nuestro caso, en la institución educativa de la $\mathrm{UPTC}^{28}$.

Partiendo de este enfoque y en un intento de generar un espacio para el diálogo de saberes, teorías y conceptos que sustentan el proceso educativo de los diferentes programas, que establecen miradas diferentes en la formación del educador, concebimos nuestro modelo pedagógico ${ }^{29}$ como el acto del conocimiento que integra la práctica investigativa del educador y educando, como eje central en la formación de educadores con liderazgo, valores y principios éticos, mediados por la integridad profesional e identidad con el contexto histórico, social, multicultural y responsabilidad social. Y, por lo tanto, el acto del conocimiento en educación, corresponde a la interiorización de una nueva actitud respecto a la vida y el mundo que le rodea y que se construye de manera colectiva, pero el resultado final es plenamente individual, sustentado en una política, normas, enfoque educativo y en un modelo pedagógico.

Tanto el enfoque educativo como el modelo pedagógico están mediados por la ética y la integridad profesional. La filósofa española Adela Cortina nos presenta varios tipos de ética: la del discurso, la razón, la social entre otras, que "sirve para forjar un buen carácter, generar buenos hábitos que conduzcan a la justicia y a la felicidad" 30

23 Paradigma: Es un modelo epistemológico que sirve para la comprensión del mundo.

24 Ocampo conceptualiza el humanismo como el "conjunto de tendencias espirituales y filosóficas que tiene por objeto el desarrollo de las cualidades esenciales del hombre”. Cfr. Javier Ocampo López, Op. cit. (2001), p. 255. El humanismo católico estuvo inspirado en el filósofo Jacques Maritain, con el conocido enfoque neotomista. (Cfr. Jacques Maritain, La educación en este momento crucial. Bs. As. Argentina: Declée de Brouwer, 1963).

25 Al respecto puede consultarse a Pablo Guadarrama, Humanismo en el pensamiento latinoamericano, (Tunja: UPTC, 2002) Obra financiada por la Dirección de Investigaciones de la UPTC.

26 En la legislación colombiana se considera la educación como "un proceso de formación permanente, personal, cultural y social que se fundamentan en una concepción integral de la persona humana, de su dignidad, de sus derechos y de sus deberes". Ley 115 de 8 de febrero de 1994 , art. 1.

27 Esta síntesis la asimilamos de filósofos, pedagogos clásicos, colombianos como Guillermo Hoyos y el Padre Alfonso Borrero. Cfr. Diana Elvira Soto Arango. "El profesor universitario de América Latina. Hacia una responsabilidad ética-científico-social” Revista Historia de la Educación Latinoamericana $\mathrm{N}^{\circ} 13$ (2009): 166-188.

28 Nos referimos a la Facultad de Educación de la Universidad Pedagógica y Tecnológica de Colombia, primera institución formadora de docentes en el siglo XX y de ámbito nacional que en la actualidad cuenta con 35 programas de los cuales 13 de pregrado y 22 de postgrado incluyendo 4 doctorados y un postdoctorado en educación, 5960 estudiantes y 326 profesores.

29 El modelo lo concebimos como una construcción teórica, para acercarse racionalmente, a un acto del conocimiento que lo explica en sus relaciones internas con elementos y factores que inciden en el mismo.

30 Adela Cortina (2017). "Si caemos en mínimos de humanidad, entonces nos deshumanizamos”, en Revista Eafitense, No. 112, I semestre de 2017, 11-13. 
El distintivo de este modelo pedagógico está dado en el acto del conocimiento ${ }^{31}$, sustentado en el compromiso de la formación de educadores con liderazgo, principios éticos, pensamiento crítico y autónomo, con identidad en el contexto histórico, social, multicultural del país y Latinoamérica, y ciudadanos que tengan la sensibilidad ${ }^{32}$ para que todo acto de conocimiento se oriente desde la integridad profesional a la responsabilidad social, pero fundamentalmente, que se tenga identidad con su función y desempeño docente. Es más, que la profesión de educador sea parte del proyecto de nuestras vidas, donde la generosidad del educador sea un principio fundamental ${ }^{33}$.

Finalmente, indicamos que el modelo pedagógico ha presentado históricamente varios ejes centrales, sin entrar a analizarlos si es necesario que los enumeremos: Primero, la relevancia del maestro, desde Aristóteles y Santo Tomás. Segundo, la preferencia a los medios didácticos, desde Comenio. Tercero, con la notabilidad a los educandos, desde la Ilustración con Rousseau hasta Pestalozzi. Cuarto, con la preeminencia al acto del conocimiento, con posiciones diversas desde la normativa hasta posturas de contextos sociales.

\section{Enfoques Educativos y Modelos Pedagógicos en la Facultad de Educación de la UPTC, siglos XX y XXI.}

La Escuela Normal Superior, en Colombia ${ }^{34}$, se creó bajo el enfoque educativo del humanismo cristiano católico. ${ }^{35}$ Sin embargo, aunque este enfoque se ha mantenido a través del tiempo en la legislación y las prácticas cotidianas, debemos indicar que, a su vez, por los currículos de la Facultad de Educación han transitado diferentes escuelas de pensamiento que han llevado a diversos modelos pedagógicos, que se han cristalizado en los Proyectos Educativos de cada programa de Licenciatura en la UPTC.

En especial la pedagogía alemana tiene una herencia que se remonta al siglo XIX, durante la reforma instruccionista de Dámaso Zapata Vargas, ${ }^{36}$ considerado

31 Paulo Freire, Pedagogía de la indignación: cartas pedagógicas en un mundo revuelto (Buenos Aires: Siglo Veintiuno Editores, 2012), p. 47.

32 Emergencias para identificar las apuestas de los movimientos sociales, y establecer cómo estas dinámicas contribuyen con su acción a la ampliación simbólica de los significados, los saberes y las prácticas, como la probabilidad de maximizar la esperanza con relación a la probabilidad de frustración. De Sousa Santos, Boaventura, Refundación del Estado en América Latina. Perspectivas desde una epistemología del Sur (La Paz, Bolivia: Plural Editores, 2010), p. 39.

33 En el proyecto de investigación de maestras rurales hemos localizado ejemplos de vida que contrastan con las respuestas de los estudiantes de primer semestre (año 2016) de la Facultad de educación cuando indican que varios de sus docentes les plantean el cambio de carrera por no tener futuro en la docencia. Véase, resultados de entrevistas.

34 Las Escuelas Normales de Colombia y Brasil fue objeto de investigación de los estudios postdoctoral de Lima-Jardilino, en Doctorado Ciencias de la Educación, UPTC. Conferir los artículos. "Houve uma Escola Normal Superior na América Latina? O caos Brasil e Colombia", in. Revista Historia de la Educación Colombiana - Rhela No. 11, año 2008, pp. 93-106; "Formação de Professores na América: Notas sobre história comparada da Educação, século XX” in. Revista Brasileira de Pesquisa sobre Formação de Professores - RBPFP, Vol.2, No.2 p.54-67, jul-dez, 2010.

35 En Colombia, la dependencia del humanismo católico fue doctrina de Estado desde la presidencia de Rafael Núñez, en la conocida etapa de la Regeneración; al respecto la voz autorizada de Jorge Duarte Acero, La educación católica durante la regeneración. la universidad colombiana de finales del siglo XIX (1886-1898). Tesis doctoral para optar al Doctorado en Ciencias de la Educación. (Tunja: UPTC, 2016). Edición mimeografiada.

36 Amparo Galvis de Orduz, Dámaso Zapata, Maestro de maestros. (Colombia: UNAB, 2005) permite corroborar la importancia del maestro bumangués: Dámaso Zapata Vargas, especialmente por ser el creador de la llamada Reforma Instruccionista. Nacido 
el más destacado educador en liderar el método inspirado en el suizo J. H. Pestalozzi en el siglo XIX.

Cabe anotar que, con la segunda misión alemana ${ }^{37}$ en los inicios del siglo $X X$, la pedagogía tradicional, para algunos intelectuales europeos, era algo secundario, que estaba desprestigiada y aislada de la realidad que, en palabras de Giner de los Ríos, era haberse olvidado de los principios, teniendo en cuenta que las "obras de la naturaleza son obras de maestro; las obras del hombre son obras de aprendiz... Y, sin embargo, en esas obras de aprendiz es en que una pedagogía funesta se obstina en cerrar nuestra atención, dejando a un lado la realidad viva y fecunda" ${ }^{38}$. En esa crisis, que consideraban se encontraba la pedagogía, otros la ridiculizaban con frases como: "La filosofía es una vieja loca, que tiene una hija tonta: la pedagogía" ${ }^{39}$. Pero, es allí donde sale Durkheim a defender la pedagogía, reivindicando los trabajos de los pedagogos como "documentos del espíritu del tiempo" ${ }^{40}$. Sin embargo, en Colombia, lo que no se puede negar es que los principios de Johann Heinrich Pestalozzi (1746-1827), Friedrich Froebel Bardeen (1782-1852), y Johann Friedrich Herbart (1776-1841), se habían difundido y de esta manera la Pedagogía se había consolidado desde la tradición intelectual alemana, a través de las misiones pedagógicas alemanas, que habían llegado al país ${ }^{41}$.

Podemos decir que, si Kant influenció a Herbart y ellos dos consolidan la tendencia alemana, por otra parte, el francés Auguste Comte (1798-1857), fundador de la sociología y el positivismo, marcó el pensamiento de David Emile Durkheim (1858-1917) ${ }^{42}$, quien desarrolla la educación dentro del contexto

el 11 de diciembre de 1833. Hijo del Coronel Ramón Zapata y de doña Genoveva Vargas Noguera. El coronel Ramón Zapata fue un destacado militar que había acompañado a Simón Bolívar en la Campaña Libertadora de 1819, que diera la libertad a la Nueva Granada en el hoy día llamado "Puente Boyacense". Se formó inicialmente en Bucaramanga con el maestro español, José Diéguez y luego en Bogotá se forma en el Colegio San Bartolomé, donde se graduó de Doctor en Leyes y Ciencias Sociales y Políticas. Diputado a la Asamblea del Estado Soberano de Santander en 1857 y posteriormente en 1865, también fue representante elegido para representar al Estado de Santander en Bogotá en la Cámara de Representantes, siendo reelegido en 1868. En 1869 fue nombrado Ministro de Legislación de Colombia en Venezuela. A su retorno a Colombia se le nombró Superintendente de Instrucción Pública del Estado de Santander donde desarrolló un plan magisterial memorable. Fue un notable defensor de la profesión docente, y se le conoce como el más destacado ideólogo de la Ley $2^{\mathrm{a}}$ de 1870 , mediante la cual se organizó la instrucción pública y se fundaron las Escuelas Normales durante la Presidencia de Eustorgio Salgar. Trajo a Colombia la primera Misión Alemana con pedagogos de alto nivel, especialmente formados en el método pestalozziano. En 1872 fue nombrado Director de Instrucción Pública en el Estado de Cundinamarca. Colaboradores de Zapata fueron Enrique Cortés y José María Vargas. Cfr. Armando Suescún, Derecho y sociedad en la historia de Colombia, Tomo III, (Tunja: Editorial Universidad Pedagógica y Tecnológica de Colombia, 1998).

37 La primera misión alemana fue traída a Colombia en la época conocida como el Radicalismo, en la presidencia de Eustorgio Salgar, con la Reforma Educativa de Dámaso Zapata. Un recorrido histórico sobre este punto puede hacerse en el libro: Carlos Barrera Martínez, La historia de las ideas Benthamistas y Antibenthamistas en Boyacá. (Tunja: Academia Boyacense de Historia, 2010).

38 Giner señala en los principios de la educación que no "sólo se trata de informar al educando, sino de formar hombres; que no enseña conceptos o cosas, sino a pensarlos y hacerlas: en consecuencia, no intenta que sea aprendidas, sino que se aprenda hacerlas". Francisco J. Laporta, Antología pedagógica de Francisco Giner de los Ríos (Madrid: Santillana, 1977), p. 32. Francisco Giner, Educación y enseñanza Tomo XII (Madrid: Espasa Calpe, 1933), p. 41.

39 García cita a Joaquín de Entrambasaguas y a Unamuno. Joaquín García Carrasco, Teoría de la Educación (Madrid: Ediciones Anaya, 1984); J. Entrambasaguas. La papelera volcada. El envés de las letras y algo más (Madrid: Vasallo, 1974); M. Unamuno. Amor y pedagogía (Madrid: Espasa Calpe, 1946).

40 Gonzalo Cataño, "Introducción" en David Emile Durkheim, Educación y sociología (Educación and sociología) Traducción de Gonzalo Cataño s/f. (posiblemente de 1978), 82, 83, 100.

41 Con cada misión alemana se dio una reforma educativa. En la segunda de 1925, se vincularon a la misma los colombianos Tomás Rueda Vargas y Gerardo Arrubla, entre otros. En 1927 propusieron el Instituto Pedagógico.

42 David Emile Durkheim (1858-1917) ingresa a la Escuela Normal Superior de París en 1879, fue alumno de Numa Denis Fustel de Colulanges. Recibe por lecturas la influencia de Augusto Comte y Herbart Spencer. Estudió Sociología en 1885 a 1886 en Marburg, 
de la sociología. Para este sociólogo la educación es diferente a la pedagogía. En este contexto, el objeto de la educación es "adaptar al niño al medio social en que está destinado a vivir", y la pedagogía es "una teoría práctica. No estudia científicamente los sistemas de educación, pero reflexiona sobre ellos, con el objeto de facilitar la actividad del educador, ideas que le dirijan"43. Es Durkheim quien señala la construcción de la ciencia de la educación, en la cual se debe apoyar la pedagogía ${ }^{44}$.

Dentro de la corriente sociológica, se encuentra el norteamericano John Frederick Dewey (1859-1952) ${ }^{45}$, quien publica entre otras obras: "La escuela y el progreso social" (1899) y "Democracia y educación" (1916) y se le considera el creador de la Escuela Nueva ${ }^{46}$. Sus principios pedagógicos se centran en: centros de interés del alumno; aprendizaje por acción, la escuela como centro social" $^{47}$. En esta corriente también se destacan María Montessori (1870-1952) y Ovidio Decroly (1871-1932), quien estuvo en Colombia en 1925, invitado por Agustín Nieto Caballero (1889-1975) ${ }^{48}$. Pedagogos se introdujeron en Colombia a través de Nieto Caballero, quien organizó el Gimnasio Moderno (1914) ${ }^{49}$, bajo los principios de "enaltecer al individuo, prepararlo para la vida, enseñarlo a pensar en uso de la libertad, la autonomía y la creatividad" ${ }^{50}$. Lo relevante de esta tendencia es que la educación se establece como ciencia en construcción y la pedagogía se desarrolla bajo la experimentación, con ciencias auxiliares como la psicología y la sociología y el niño es el centro de la educación.

Otro difusor de la Escuela Nueva en Latinoamérica fue el español Lorenzo Luzuriaga Medina (1889-1959) $)^{51}$, quien perteneció al grupo de españoles socialistas $^{52}$ que se exiliaron en Latinoamérica, durante el período del dictador Francisco Franco. Luzuriaga desarrolló las ideas educativas de sus maestros

Berlín y Leipzig. En 1887 enseña en la Universidad de Bordeaux y dicta un curso de Ciencias sociales y de pedagogía y une la pedagogía con la sociología. En 1895 publica las reglas del método sociológico.

43 Gonzalo Cataño. Op. cit., (1978): 82, 83, 100.

44 Indica que "la ciencia de la educación no existe más que en Estado de proyecto" y la sociología y la psicología en las cuales se debe apoyar la educación están en construcción, ver: Gonzalo Cataño, Op. cit., (1978): 116.

45 John Frederick Dewey (1859-1952). Publicó La escuela y el progreso social (1899). Democracia y educación (1916) Fue presidente de la asociación de filosofía y de piscología en Norte América. Publicó unos 700 artículos y 40 libros. John Dewey. Experiencia y educación (Buenos Aires: Editorial Losada, 1943).

46 Calvache resume los principales aportes de la escuela nueva en: actividad, globalización de contenidos, interés, individualización, sociabilización, colaboración escuela familia" y el principio fundamental se centra en que la educación debe estar dada por los intereses de los alumnos". José Edmundo Calvache López. "La escuela nueva y los conceptos básicos de la educación en el pensamiento de John Dewey. Una aproximación teórica”, Revista Historia de la Educación Latinoamericana $\mathrm{N}^{\circ}$ 5, (2003): $107,110$.

47 Heladio Moreno. Biografía de grandes pedagogos (Bogotá: Editora Géminis), 61.

48 Véase un estudio monográfico sobre Agustín Nieto Caballero en Revista Historia de la Educación Latinoamericana- No. 5 (2003).

49 Agustín Nieto Caballero. Una escuela. (Bogotá. Editorial Antares Tercer Mundo, 1966; Tomás Rueda Vargas, El Gimnasio Moderno (Usaquén: Editorial San Juan Eudes, 1945).

50 Agustín Nieto Caballero. "Principios de la Escuela Nueva" Revista Historia de la Educación Latinoamericana N 5 (2003): 141.

51 Lorenzo Luzuriaga Medina (1889-1959), pedagogo español que se exilió en Argentina y murió en Buenos Aires.

52 La influencia del exilio republicano español tiene una marcada influencia en la educación colombiana. En Colombia eran emulados por fuerzas del recientemente creado partido comunista y las ideas socialistas en ascenso, emparentadas con el nacional populismo gaitanista. En particular, ejercieron influencia en la generación que se formó en la Universidad Nacional, de la cual da testimonio el Dr. Armando Suescún, quien fuera rector de la UPTC. Destacamos al eminente José María Ots Capdequí (Valencia, 1893 Benimodo, 20 de septiembre de 1975) especialista en Derecho colonial Indiano. 
Francisco Giner de los Ríos (1839-1915) ${ }^{53}$, José Ortega y Gaset $(1883-1955)^{54}$ y el pensamiento de la Institución Libre Enseñanza ${ }^{55}$ y se hizo vocero de la obra pedagógica de John Dewey, realizando traducciones de este autor, que ya había iniciado en España en $1916^{56}$. Reiteramos que, en este sentido, se puede considerar a Luzuriaga como un difusor de la Escuela Nueva, especialmente, por los trabajos publicados a través de la "Revista de Pedagogía", que organiza en 1922, en Madrid. Es más, propuso durante la Segunda República española, el programa escolar de la "escuela única, activa, pública y laica" 57 y en 1932 publicó el libro La escuela única. Posteriormente dio a conocer una amplia bibliografía sobre la Escuela nueva en Buenos Aires, desde 1944, a través de la Colección Pedagógica, de la editorial Losada, conformada por expatriados republicanos españoles, dio a conocer una amplia bibliografía sobre la Escuela Nueva. Debemos destacar, igualmente, que estableció relación académica con educadores como Pedro Enríquez Ureña, quien hacia 1946 enseñaba en la Universidad de la Plata y era accionista de la editorial Losada, que dirigía Luzuriaga. Además, se localiza en sus trabajos la influencia de las publicaciones de la Institución Libre Enseñanza de Giner de los Ríos ${ }^{58}$.

Como se ha señalado, Luzuriaga desarrolla en su exilio en Argentina, una línea de publicaciones en educación de las que podemos destacar la Historia de la educación y de la pedagogía, texto clásico en las facultades de educación en Latinoamérica y en Colombia. En este libro define la educación "como la influencia intencional y sistemática sobre el ser juvenil, con el propósito de formarlo y desarrollarlo... La educación es así una parte integrante, esencial, de la vida del hombre y de la sociedad. La pedagogía, indica, es la reflexión sistemática de la educación. La pedagogía es una ciencia del espíritu que está

53 Francisco Giner de los Ríos (1839-1915) fue director de la Institución Libre de Enseñanza (ILE). Véase Giner, Francisco, Educación y enseñanza. (Madrid, Espasa Calpe, Tomo XII, 1933), p. 20. Obras completas de Francisco Giner se publicaron en 1889 en la Biblioteca Andaluza. Los trabajos de este tomo fueron publicados por Giner en el Boletín de la Institución Libre de Enseñanza. En este texto analiza la situación de los maestros españoles de fin del siglo XIX, con la extrema pobreza, de salarios de 125 pesetas anuales ganado según él menos que el "harapiento bracero", 20.

54 José Ortega y Gasset (1883 - 1955) estuvo exiliado en Argentina hasta 1942 cuando se va para Portugal. Fue profesor de la Escuela Superior de Magisterio de Madrid (1909). Al igual que Luzuriaga estudio en Alemania. Pertenece al movimiento denominado novecentismo.

55 La Institución Libre de Enseñanza o ILE, fue fundada por Francisco Giner de los Ríos en 1876 en España. Esta institución se originó por un grupo de docentes, de la Universidad Central de Madrid, como un acto de rechazo al hecho de haberse suprimido en la Universidad Central de Madrid la libertad de Cátedra. La corriente filosófica que sustentó esta institución fue la de Karl Christian Friedrich Krause Karl Christian Friedrich Krause (1781-1832), filósofo alemán que desarrolló el panenteísmo y que sustentó teóricamente el krausismo. El Dios del panenteísmo es el creador y la energía vital del universo, así como la fuente de la ley natural, por lo que es trascendente e inmanente.

56 Obras como "Mi credo pedagógico" de Laurent Bonardi, Dewey. "Les intellectuels espagnols exilés dans l’argentine peroniste", Haol, No. 5 (2004): 53-64, consultada en línea. En este artículo se destaca la producción académica de los exiliados españoles en Argentina. Véase una amplia biografía en wikipedia.org/ wiki/Lorenzo_Luzuriaga, consultada el 30 de mayo del 2013.

57 De su obra del exilio, con trascendencia en Latinoamérica, se localizan entre otras: La educación nueva (1942); La pedagogía contemporánea (1942); Reforma de la educación (1945); Historia de la educación pública (1946); Pedagogía (1950); Pedagogía social y política (1954); Antología pedagógica (1956); La Institución Libre de Enseñanza y la educación en España (1957); Diccionario de pedagogía, obra póstuma; Historia de la educación y de la pedagogía (1961) en el año 1991 llevaba 21 ediciones.

58 Pedro Henríquez Ureña, Universidad y Educación (México: UNAM, 1969), p. 40. Defensor de la Universidad Nacional que había fundado Justo Sierra en 1910 y conceptúa sobre la universidad como "la institución destinada a cumplir fines de alta cultura y de cultura técnica, 58. Se localiza en sus escritos que cita a Francisco Giner de los Ríos, 86. 
en íntima relación con la filosofía, la psicología, la sociología y otras disciplinas, aunque no depende de ellas, ya que es una ciencia autónoma" ${ }^{\prime 59}$.

La influencia del exilio republicano español en la educación colombiana merece un apartado especial. ${ }^{60}$ Entre los profesionales que emigraron a Colombia encontramos un alto porcentaje de universitarios, incluso algunos docentes que ejercían en España, y entre ellos venían pedagogos. En el gobierno de Alfonso López Pumarejo dos intelectuales: Francisco Abrisketa y Andrés Perea Gallaga. Francisco "Patxi", Abrisketa fue profesor de estadística y economía en la Universidad Nacional de Colombia así como en la Universidad Pontificia Javeriana en Bogotá. Por su parte, Andrés Perea Gallaga, realizó el primer censo de Colombia, y su hijo José Perea Sasián fue profesor en la Facultad de Medicina de la Universidad Nacional. Luis de Zulueta Escolano es el más reconocido de los exiliados republicanos españoles. Eduardo Santos, quien luego sería presidente colombiano, al conocerlo en París, le ofreció emigrar a Colombia, y le encomienda su responsabilidad en el periódico El Tiempo de su propiedad. Sin embargo, no se parta de su vocación docente, ejerciendo en la Universidad Nacional, la Escuela Normal Superior, el Instituto Pedagógico Nacional o la Universidad de los Andes, que él ayudó a fundar. El aporte en la pedagogía de la Escuela Normal Superior se hizo notar, y sin duda cuando regresa a Tunja la institución, tendría nuevos aires renovados que serían determinantes para la creación de la UPTC. Igualmente, recordamos las mujeres republicanas ${ }^{61}$ hicieron su aporte como es el caso de Mercedes Rodríguez Bellido que fue contratada por la Escuela Normal Superior, con la creación dentro de la Escuela Normal del Instituto de Psicología Experimental.

Se cerró la muestra de profesionales que dieron su aporte a la docencia, con la recuperación para la historia de la educación colombiana de los siguientes: "Fernando Martínez Dorrien, fue uno de los primeros exiliados a Colombia y contribuyó de manera especial a la difusión cultural con la fundación de la revista Estampa, la primera en utilizar el huecograbado en Colombia; José de Benito, catedrático de Derecho Mercantil en España, laboró en el periódico bogotano El Tiempo, propiedad de la familia Santos, cuando volvió a España recobró su plaza en la Universidad de Zaragoza; Felipe Andrés Cabezas, había sido profesor de Literatura en la Universidad de Salamanca, especialista en Luis Vives, en Colombia fue profesor de Lengua española en Ocaña, departamento del Norte de Santander; Antonio Fabra Rivas, sociólogo, fue profesor de la Universidad del Cauca y de la Escuela Superior de Agricultura de Colombia; el catalán Francisco del Olmo Barrios, fue jefe de Educación Pedagógica de la Dirección de Educación

59 Lorenzo Luzuriaga, Op. cit. (1961) Historia de la educación y de la pedagogía, pp. 11, 12. Clasifica la pedagogía contemporánea en: individual; psicológica-experimental; activa; social, y filosófica, Lorenzo Luzuriaga, Op. cit. (1961), p. 247.

60 En Colombia eran emulados por fuerzas del recientemente creado partido comunista y las ideas socialistas en ascenso, emparentadas con el nacional populismo gaitanista. En particular, ejercieron influencia en la generación que se formó en la Universidad Nacional, de la cual da testimonio el Dr. Armando Suescún, quien fuera rector de la UPTC. Destacamos al eminente José María Ots Capdequí (Valencia, 1893 - Benimodo, 20 de septiembre de 1975) especialista en Derecho colonial Indiano.

61 María Eugenia Martínez Gorroño, españolas en Colombia. La huella cultural de las mujeres exiliadas tras la guerra civil. (Madrid: Fundación Españoles en el Mundo, 1999). 
Nacional del Atlántico y profesor de la Escuela Industrial de Barranquilla; Santiago Sentís Melendo, magistrado en España, fue docente del colegio Colón de Barranquilla, en Colombia; Ignacio Vidal Guitart fue director de la Escuela de Agricultura de Cali; Marco Aurelio Vila fue profesor en la Universidad de El Rosario y director de varios internados en Bogotá. El geógrafo Pau Vila i Diñares fue profesor en la Universidad Nacional; Pablo Ardua, geógrafo, elaboró la primera geografía con parámetros modernos en Colombia, también impartió clases en el prestigioso Colegio Mayor San Bartolomé de la capital colombiana; José Francisco Cirre, profesor de Literatura en la Escuela Normal Superior, marchó a Estados Unidos junto con su esposa, Manuela Manzanares, quien trabajó en la Biblioteca Nacional de Colombia; Pedro Villa fue el primer rector del más prestigioso centro de enseñanza primaria y secundaria, el Gimnasio Moderno; y allí y en la Universidad Pedagógica Nacional también incursionó el español socialista José Prat. Manuel Usano Martín, cirujano, quien había sido profesor ayudante en la Universidad de Valencia, en Colombia, fue profesor de la Escuela Normal Superior.

El galeno Carlos Zozaya Balza fungió como titular de Parasitología y Enfermedades Tropicales en la Universidad Pontificia Javeriana y en la Universidad Nacional, terminó como profesor en la Autónoma de Caracas; el arquitecto Esteban de la Mora, quien construyó y proyectó la Plaza de Toros de Bogotá, fue profesor de Urbanismo en Bogotá; los hermanos Manuel y Enrique García Reyes trabajaron como profesores en la Escuela de Ingenieros de Bogotá. Antonio Fabra Rivas, uno de los organizadores de la semana trágica de Barcelona en 1909, fue profesor de la Universidad de Popayán, en Colombia." 62 Algunos de los transterrados encontraron en la docencia el ejercicio de su formación técnica que en Boyacá fue muy importante para el desarrollo de las ingenierías y las empresas como Acerías. ${ }^{63}$ El principal mecenas de los maestros españoles fue el ministro de Educación, Germán Arciniegas.

Por su parte, en Inglaterra localizamos a Herbert Spencer (1820-1903) con su obra: Educación intelectual, moral y física (1861) y a Alexander Bain (1818-1903) filósofo influenciado por Compe, que escribió el texto Education as a Science (1879) y a William James (1842-1910) con su obra Charlas a los maestros (1899), donde el objeto de la educación era desde los recursos biológicos, la formación de hábitos de conducta. ${ }^{64}$ Hacemos un inciso, porque no podríamos dejar de citar la herencia inglesa en el pensamiento pedagógico Colombiano, en especial la Pedagogía Lancasteriana ${ }^{65}$ y el pensamiento de Jeremías Bentham ${ }^{66}$. Podríamos

62 José Ángel Hernández García, "La influencia pedagógica del exilio republicano español: la edad de oro de la enseñanza en Colombia". Revista Latinoamérica $\mathrm{N}^{\circ} 54$ (2012) México. http://www.scielo.org.mx/scielo.php?script=sci_ arttext\&pid=S1665-85742012000100006. Consulta, 10/10/17

63 Acerías Paz del Río fue creada en 1948, y es la segunda empresa siderúrgica más grande de Colombia, propiedad actualmente del grupo empresarial brasilero Votorantim Group. La UPTC creó la Escuela de Metalurgia para fortalecer esta importante empresa nacional responsable del $30 \%$ de la fabricación de acero en este país.

64 Lorenzo Luzuriaga, Op. cit. (1961), p. 249.

65 Javier Ocampo López, Santander y la Educación. (Tunja: Colegio de Boyacá, 1987).

66 La influencia inglesa en la pedagogía colombiana tiene su antecedente más importante en el desarrollo del pensamiento de Jeremías Bentham. Fue fundamental para la conformación de las ideas liberales en el país. Un recorrido histórico sobre este punto puede 
decir que la herencia cuáquera protestante, tuvo su primera manifestación en la pedagogía colombiana a través de la pedagogía de Joseph Lancaster. Según el historiador Luis Bohórquez Casallas fue en la región andina venezolana que se fundó la primera escuela lancasteriana: "en 1821, en Capacho, pueblo cercano a Cúcuta, el padre Mora fundó la primera escuela lancasteriana de la América Meridional, convirtiendo el libre examen del inglés hacia la moral cristiana. El general Santander conoció a fray Mora y lo trajo para convertirlo en mentor de la niñez en la Gran Colombia (...) En vista de los excelentes resultados y cualidades docentes del franciscano, el Gobierno lo envía por el Cauca y el Ecuador a propagar el nuevo sistema." ${ }^{67}$ Juan Sebastián Mora se convirtió en el pilar fundamental de la Escuela Lancasteriana en la Gran Colombia. Santander tuvo noticias de él "en septiembre de 1821, sacándolo de su pueblo andino, para encargarlo del adiestramiento de los preceptores lancasterianos, con el objeto de que, una vez preparados en número suficiente, fueran a otras ciudades con el propósito de adiestrar a otros. Un viajero británico, que pasó por Capacho a fines de marzo de 1823, halló que la partida de Mora había significado el cierre de su escuela." ${ }^{68}$ Las escuelas Lancasterianas tuvieron como centro de irradiación a Bogotá, luego el sur de la Nueva Granada y Guayaquil. El 25 de julio de 1824, encontramos referencias de "el religioso franciscano Fray Sebastián Mora a quien el gobierno destinó a difundir la enseñanza mutua en los departamentos del sur, en su tránsito por Cali ha dejado planteada en aquella ciudad la escuela de primeras letras conforme a este método y con toda la regularidad y orden posible, en un salón que caben más de ciento ochenta niños. Es muy notable la franqueza con que todo el vecindario de Cali se ha prestado a facilitar los auxilios necesarios para este establecimiento que su patriotismo reclamaba; pero muy particularmente se ha hecho digno de aprecio el celo con que el Dr. Vicente Lucio Cabal y el R. Padre Fray Ignacio Ortiz ha propendido a su fundación." ${ }^{69}$

Asimismo, debemos indicar que el francés, en el siglo XX, por ejemplo, Maurice Debesse (1903-1998) estableció las etapas de la educación desde la psicología ${ }^{70}$, como lo haría Jean Piaget (1896-1980) desde la biología, donde desarrolla la pedagogía genética ${ }^{71}$. Esta tendencia, llega hacia finales de década

hacerse en el libro: Carlos Barrera Martínez, La historia de las ideas Benthamistas y Antibenthamistas en Boyacá. (Tunja: Academia Boyacense de Historia, 2010).

67 Luis Bohórquez Casallas, La Evolución Educativa en Colombia. (Bogotá: Publicaciones Cultural Colombiana, 1955) 265.

68 Edgar Vaughan, (1987) Lancaster en Caracas (1824-1827). (Caracas: Ministerio de Educación, 1987) 78.

69 Gaceta de Colombia. 18 de julio de 1824. №. 145.

70 Se debe considerar que, el modelo francés y sus métodos estuvieron presente en la Escuela Normal de Latinoamérica, ejerciendo cierta hegemonía en los paises del cono sur, en especial Brasil, Argentina y ortros países, como México. Aunque la institución de formación de maestros en Colombia tuvo la marcada influencia del modelo alemán, en el siglo veinte, fue marcada por influencia hegemónica de pensamiento fracés, basada en ideal de una educación humanística. Véase, Lima-Jardilino, (2008; 2010 op.cit).

71 Jean Piaget. ¿A dónde va la educación? (Buenos Aires: Editorial Teide, 1980); J. Piaget. La psicología de la inteligencia (Buenos Aires: Editorial Psique, 1971). "Según Piaget, las etapas del desarrollo cognitivo son: 1) etapa sensorio-motora (0-2 años) donde los niños muestran una vivaz e intensa curiosidad por el mundo que les rodea, su conducta está dominada por las respuestas a los estímulos; 2) etapa pre operacional (2-7 años) en la que el pensamiento del niño es mágico y egocéntrico, creen que la magia puede producir acontecimientos y los cuentos de hadas les resultan atrayentes, además se cree el centro de todos los sucesos, que todas las cosas giran en torno a él, resultándole muy difícil ver las cosas desde otro punto de vista; 3) etapa de las operaciones concretas (7-11 años), el pensamiento del niño es literal y concreto, puede comprender que $8+11=19$, pero la formulación abstracta, como la de una ecuación algebraica, sobrepasa su captación, y 4) etapa de las operaciones formales en el nivel adulto, es capaz de realizar altas abstracciones y 
de 1970 a la Universidad Pedagógica Nacional, en Bogotá a través de la Dra. Mariana Flórez, quien regresaba de hacer un doctorado en Ginebra, donde tuvo la oportunidad de ser estudiante del gran maestro Piaget. Recuerdo ${ }^{72}$ que un sector de la Facultad de Educación, que ya había tomado posición hacia la tecnología y se apoyaban en la Asociación de Psicólogos, presidida por el Dr. Rubén Ardila ${ }^{73}$, estableció una atmósfera de crítica hacia la nueva corriente, que se iniciaba en este claustro universitario. El hecho es que pronto las teorías de Piaget, David Ausubel (1918-2008) ${ }^{74}$ y Novak $(1932)^{75}$ se fueron contraponiendo a la tendencia conductista predominante en ese momento ${ }^{76}$. Los libros clásicos que se utilizaron en los cursos fueron el de Estudios de Psicología Genética, y el de Hacia dónde va la educación, ambos de Piaget ${ }^{77}$. Por otra parte, el Dr. Gonzalo Cataño promulgaba, desde la cátedra, la pedagogía bajo la visión teórica de Emilio Durkheim. Es también comentar que, la UPTC en Tunja, ofrecía la Licenciatura en Psicología Educativa, y allí entre 1968 y 1974, la corriente del pensamiento pedagógico que primó fue la de Sigmund Freud (1856-1939), ${ }^{78}$ Erickson y Adler, entre otros, a través del profesor Noé Ardila ${ }^{79}$.

Hay que añadir que Gastón Mialaret (1918) desarrolló la conceptualización de Ciencias de la Educación ${ }^{80}$, hacia la década de 1970. Precisamente, con Mialaret, continuando con la cientificidad, se plantea la interdisciplinariedad de las Ciencias de la Educación. La institución educativa, según este pedagogo, no está aislada de la sociedad y la relaciona en su estudio de manera interdisciplinaria, con otros campos del conocimiento, como son, entre otros: la Historia de la Educación y de la Pedagogía; Sociología de la Educación; Demografía Escolar; Economía de la Educación; Pedagogía comparada y la Psicosociología. Un hecho relevante en Francia es la creación, en 1967, de los estudios de Ciencias Sociales de la Educación en la Facultad de Letras. Hay que decir, que en el plan

efectuar (11-15 años), aquí el niño ingresa inferencias, es la etapa correspondiente a las facultades superiores de los seres humanos".

72 Este recuerdo (memoria) que se incluye en la pedagogía con la dificultad espacio-temporal. En nuestro caso se sustenta en el recuerdo y en la bibliografía de los programas académicos que se desarrollaban en la Facultad. En el año 1980 el señor decano de la Facultad de Educación me citó a su oficina para que explicará por qué en el curso de psicología de la educación se incluía a Piaget. J.C. Mèlich. Filosofía de la finitud (Barcelona: Editorial Herder, 2002), 35.

73 Psicólogo colombiano que fundó la Revista Latinoamericana de Psicología en 1969 y en 1970 publica su libro Psicología del aprendizaje, México, Siglo XXI. Este texto se utilizó en toda la década de los setenta en un gran número de universidades colombianas.

74 Ausubel, desarrollo "los organizadores previos" (1960) utilizados en la psicología del aprendizaje. Véase: David Ausubel, Educational Psychology. A Cognitive View (New York: Holt, Rinehart \& Winston, 1968).

75 Indica "la teoría de la educación expuesta en este libro ha hecho especial hincapié en el aprendizaje cognitivo y en particular en el aprendizaje de conceptos". Joseph Donald Novak, Teoría y práctica de la educación (Madrid: Alianza, 1983), 191. Primera edición de 1977. Desarrolló los mapas conceptuales y aprendizaje significativo dentro de la corriente de Piaget.

76 En los años 1980 a 1982 se estableció por parte de Diana Elvira Soto Arango en la UPN los ciclos de conferencias sobre Tendencias pedagógicas, donde en varias ocasiones nos acompañó el pedagogo Alberto Merani. Véase plegables en Archivo DSA.

77 Jean Piaget, Psicología Genética (Buenos Aires: EMECÉ Editores, 1973), primera edición. Traducido por Antonio Battro.

78 Freud Sigmund (1856-1939), fundó el psicoanálisis y estableció las etapas del desarrollo humano desde esta concepción teórica.

79 La psicología educativa que él impartía en la Universidad Pedagógica y Tecnológica de Colombia, años 1968-1975, se sustentaba en las teorías de Freud.

80 Alicia Ramón García, “Introducción” en Gastón Mialaret. Ciencias de la Educación Trad. Alicia Ramón García (Barcelona: Edit. Oikos-tau, 1981), 117; Gastón Mialaret. Psicología de la educación (México: Siglo XXI Editores, 2006) segunda edición en español. Primera edición en francés 1996. Tanto Gastón Mialaret (1988) como Jacques Ardoino (2000), indican la necesidad de captar el proceso de enseñanza-aprendizaje en su complejidad y en sus dimensiones multireferenciales. 
de estudios de la especialización en Ciencias Sociales en la UPTC, en 1964, se localizan en la formación básica común, 5 cursos en lo que se denominó cultura pedagógica; en la cultura humanista, 3 cursos; en la cultura religiosa 3 cursos; en inglés con 3 cursos; matemáticas y física 1 curso, igual que el castellano ${ }^{81}$.

Como puede verse, en esta tendencia francesa, el planteamiento central es la interdisciplinariedad en la educación. Es allí, donde se asimilan todas las disciplinas interesadas en el estudio científico de los distintos aspectos de la educación, en sociedades y culturas determinadas, vinculando la institución educativa a la sociedad. Desde esta perspectiva, Avanzini ${ }^{82}$, ubica las Ciencias de la Educación en dos dimensiones. En primera instancia, agrupa diferentes disciplinas como la Psicología, la Sociología, la Historia y la Filosofía, pero cada una mantiene su independencia al estudiar el hecho educativo. La segunda, corresponde al proceso de constitución del saber interdisciplinario, donde se contrastan metodologías ante el mismo objeto de estudio. En este mismo sentido, se resaltan los planteamientos de Avanzini, cuando plantea dos referentes significativos para la educación colombiana: la pluralidad y el sentido abierto de las investigaciones en las Ciencias de la Educación. Esta corriente teórica de las Ciencias de la Educación, sustentada en la interdisciplinariedad, se introdujo en Colombia, entre otros programas, a través del Doctorado en Ciencias de la Educación de RUDECOLOMBIA ${ }^{83}$, que presenta un alto impacto nacional, regional e institucional, a través de 8 universidades públicas, con 320 estudiantes y 226 tesis de graduados. La UPTC a este doctorado ha aportado 62 graduados y tiene 60 tesis en desarrollo. Además, ofrece un postdoctorado en Ciencias de la Educación, reconocido a nivel internacional, que lleva 4 cohortes $^{84}$.

Resulta interesante encontrar al pedagogo latinoamericano Ricardo Nassif (1924-1984) ${ }^{85}$, profesor de Filosofía y Ciencias de la Educación en la Universidad Nacional de la Plata, Argentina. Este educador desarrolló lo que denominó pedagogía de síntesis y se preocupó por la formación de los docentes, enmarcados en la investigación interdisciplinaria. Por otra parte, se enfoca en la corriente de la pedagogía crítica que, años antes, Pedro Henríquez Ureña había propuesto en esta universidad, como una pedagogía popular.

81 Archivo Universidad Pedagógica y Tecnológica de Colombia, Especialización en Ciencias Sociales, 1964. Los cursos fueron analizados en la tesis doctoral citada de Carlos Ramiro Bravo Molina (2003).

82 G. Avanzini. La pedagogía en el Siglo XX (Madrid: Marcea, $2^{\circ}$ edición 1979). Véase las referencias sobre Freud, 108-111. Piaget y Wallon, 115-116. Dewey, 193-194. Cousinet, 195-197. Célestin Freinet, 198. La educación permanente, 293-318.

83 Documento Conceptual del Doctorado en Ciencias de la Educación, Bogotá, RUDECOLOMBIA, 1997. Archivo Doctorado en Ciencias de la Educación, Universidad Pedagógica y Tecnológica de Colombia, Archivo Diana Elvira Soto Arango, Fondo documental RUDECOLOMBIA.

84 Se sustenta este programa de investigación en los grupos HISULA e ILAC, que presentan líneas de investigación en: Historia y Prospectiva de la Universidad Latinoamericana., Universidad y Nación, Formación de educadores y en el pensamiento Ilustrado de América Colonial. El impacto, es relevante en los contextos nacional e internacional por las publicaciones y eventos que han coordinado en 25 países. Están clasificados en A Colciencias.

85 Obras: Ricardo Nassif. Pedagogía General (Editorial Kapelusz, 1958); Pedagogía de nuestro tiempo: hechos, problemas y orientaciones (Editorial Kapelusz, 1960); Teoría de la Educación. Problemática pedagógica contemporánea, (Madrid: Editorial Cincel, 1980); Las Tendencias Pedagógicas en América Latina (1960-1980), en El Sistema Educativo en América Latina (Argentina: Editorial Kapelusz, 1984); Dewey, su pensamiento pedagógico (Buenos Aires: Centro Editor de América Latina, 1992; Spranger, su pensamiento pedagógico (Buenos Aires: Centro Editor de América Latina, 1993). 
Hay que decir que, después de la segunda guerra mundial y hasta la caída del muro de Berlín en 1989, los países socialistas de Europa Oriental, incluyendo a la República Democrática Alemana, comenzaron a utilizar la denominación de Ciencias Pedagógicas. Cuba, influenciada por la Academia Rusa, también pertenece a esta tendencia. Quizá, al brasileño Paulo Freire (1921-1997) ${ }^{86}$ lo ubiquemos en esta preferencia, por desarrollar el concepto de identidad cultural y educación, pero fundamentalmente en sus obras la Pedagogía del oprimido (1967) y la Pedagogía de la esperanza (1993), expresa su gran preocupación por "qué tipo de educación necesitan los hombres y mujeres del próximo milenio, para vivir este mundo tan complejo de globalización capitalista de la economía"87. Igualmente, Edgar Morín nos enseña, los siete saberes necesarios, entre los que destacamos la ética de la comprensión (el bien pensar y la introspección) y la ética del género humano (individuo-sociedad) ${ }^{88}$

Ahora bien, en América Latina, después de la influencia y los adaptacionismos que se dieron a la Escuela Nueva, las corrientes educativas fueron permeadas por la influencia norteamericana. Desde los años 70 la tecnología educativa, con Burrhus Frederic Skinner $(1904-1990)^{89}$, aparece en los planes de estudio de las facultades de educación colombianas y en las primeras maestrías en educación que se organizaban en la Universidad Pedagógica Nacional. Por lo tanto, el énfasis estaba en la educación programada ${ }^{90}$, que se concebía como un producto de la tecnología educativa, si entendemos por esta, el empleo de instrumentos o máquinas en determinado proceso o método ${ }^{91}$. Pero por otra parte, educadores como Darcy Ribeiro (1922-1997) con el experimento de la Universidad en Brasilia en 1971, señalaban nuevos caminos y nuevas formas de administración y docencia en una universidad latinoamericana ${ }^{92}$.

En la década de los 90 se establecieron en toda Latinoamérica reformas educativas, con fuerte acento en los planes curriculares sustentadas en objetivos, que fueron desplazados por las competencias, en las guías de clase que se les enseñaban a los futuros educadores, en la práctica docente de su formación como licenciados en cómo organizar los saberes de enseñanza por medio de búsqueda

86 Paulo Freire, La Educación como práctica de la libertad (Buenos Aires, Siglo XXI Editores, 1969); Paulo Freire, Cartas a quien pretende enseñar (Buenos Aires, Siglo XXI Editores, 2002).

87 Citado por Javier Ocampo. "Identidad cultural y educación en Paulo Freire", Revista Historia de la Educación Latinoamericana $\mathrm{N}^{\circ}$ 10, (2008): 28-29; José Rubens Jardilino, "Paulo Freire. Filósofo, pedagogo e cientista social” Revista Historia de la Educación Latinoamericana $N^{\circ} 10,(2008)$ : 45-47.

88 Edgar Morín. Los 7 saberes necesarios para la educación del futuro (Medellín, Editorial Santillana, 1999. Traducción de Mercedes Vallejo Gómez), pp. 55-56.

89 Psicólogo norteamericano, inicia sus investigaciones en el laboratorio animal en 1931 en su libro Tecnología de la enseñanza, publicado en 1970, resume una serie de artículos donde sienta las bases y desarrolla los principios que rigen la educación programada. Skinner expone en sus obras de manera sistemática las técnicas conductuales que ha elaborado a través de sus investigaciones con personas y animales.

90 Diana Soto Arango, Fredy Mesa Jiménez, Orlando Caro “Convergencia Digital en la Universidad Colombiana” Revista Historia de la Educación Latinoamericana $\mathrm{N}^{\circ} 19$ (2012): 265-300.

91 J. Armsey y Norman C. Dahll. Tecnología de la enseñanza. Centro Regional de Ayuda Técnica, Agencia para el desarrollo Internacional AID (México: Editorial Guadalupe, 1973), p. 17.

92 Véase el número monográfico de la Revista Historia de la Educación Latinoamericana. Dedicado a Darcy Ribeiro (1922-1997), Número 8, 2006, Tunja, Universidad Pedagógica y Tecnológica de Colombia, RUDECOLOMBIA, Sociedad de Historia de la Educación Latinoamericana. (2006): 161-180. 
de las llamadas habilidades de los estudiantes. Competencias y habilidades fueron las consignas de esas Reformas basadas en las exigencias del capital.

Si bien la discusión por los objetivos se localizaba en Estados Unidos, en los años 60, hay que decir que a Colombia nos llegaron autores, a los claustros universitarios, en los 70, a través de Benjamín Bloom, para orientar la formación de los docentes por medio de la taxonomía. Él considera que "los objetivos (finalidades) y técnicas de medición pueden ser especificados de un modo casi ilimitado, los comportamientos de los estudiantes, implicados en dichos objetivos, pueden representarse mediante un número relativamente pequeño de clases. Por tanto, esta taxonomía se ha diseñado para ser una clasificación de los comportamientos de estudiantes, que representan los resultados que se pretenden obtener del proceso educativo"93. No menos importante fue Robert Gagné, quien desarrolló las teorías del condicionamiento del aprendizaje ${ }^{94}$ y Elliot Eisner con los objetivos en el currículo ${ }^{95}$. Por otra parte, Stenhouse que adopta la concepción del currículo desde la Sociología y lo define como: "una tentativa para comunicar los principios y rasgos esenciales de un propósito educativo, de forma tal que permanezca abierto a la discusión crítica y pueda ser trasladado efectivamente a la práctica" ${ }^{\prime 96}$.

Es en este contexto, un buen número de profesores universitarios colombianos salieron a realizar sus doctorados a diferentes países de Europa y regresaron con nuevos conceptos y miradas, que se iban introduciendo en programas y en planes de estudio para las facultades de educación ${ }^{97}$. Resultado de ello, surgen propuestas o alternativas que marcan la historia de la educación superior en Colombia y propiamente trazan las directrices de lo que deberían ser las Ciencias de la Educación.

Podemos señalar que, en los años 80, las teorías del filósofo francés Michel Foucault (1926-1984), ingresaron en el ambiente universitario colombiano, donde lo tomaban como referente, principalmente, por la metodología esbozada en su obra la Arqueología del saber (1969). El impacto se quedó en un grupo reducido de intelectuales debido a la terminología específica que manejaban y no trascendió en nuevos paradigmas de formación de los educadores colombianos ${ }^{98}$. Sin lugar a dudas, los escritos de Foucault fueron controvertidos entre los académicos de Europa y América Latina. Su obra es extensa y los conceptos de saber, poder y el discurso fueron evolucionando ${ }^{99}$. Sus obras junto con las de Basil Bernstein

93 Benjamín Bloom y colaboradores, Taxonomy of Educational objectives, I. Cognitive Domain (Londres: Longman, 1956, 1984), 12-13.

94 Robert Gagné, Las condiciones del aprendizaje (México: Editorial Interamericana, 1965).

95 Elliot Eisner, Instructional and expressive educational objectives. Their formulation and use in curriculum, en Objectives and Instruction (1969), 1-18. http://files.eric.ed.gov/fulltext/ED028838.pdf (Fecha de consulta 5 de Agosto de 2010).

96 Lawrence Stenhouse. Investigación y desarrollo del currículo (Madrid: Ediciones Morata, 1984), p. 29.

97 No es extraño, por tanto, que las ocho universidades regionales de RUDECOLOMBIA, que adelantaron su primer doctorado, lo denominaran "Ciencias de la Educación", en la experiencia de este doctorado con profesores que habían realizado sus estudios en diferentes áreas de las Ciencias Humanas, tomaron la decisión de orientar este doctorado desde la corriente interdisciplinaria sustentándose en teóricos franceses, españoles y latinoamericanos.

98 En un inicio el grupo indicaba la pedagogía como disciplina y luego como saber, donde el maestro es fundamental en el proceso. Véase en Alejandro Álvarez Gallego, "Del saber pedagógico a los saberes escolares" Revista pedagogía y saberes, N 42 (2015): 24.

99 Así lo confirma un miembro del grupo que se denominó de la práctica pedagógica cuando indica. 
(1924-2000), sociólogo y lingüista británico, ingresaron fundamentalmente en los programas de Filosofía, Sociología y Comunicación.

Es necesario tener en cuenta que, en los albores del siglo XXI, arrastramos el componente de las competencias, que ya se habían instalado, hacia los años 60, para las demandas laborales, y en los 90 en la educación ${ }^{100}$. En la facultad de educación bajo la decanatura del profesor Alfonso Tamayo, se dio una renovación pedagógica al darle relevancia a la misma, desde una conceptualización de Foucault ${ }^{101}$.

Actualmente nos encontramos en nuestras instituciones educativas de formación de docentes, incluyendo en los Documentos Maestros, para presentar al Ministerio de Educación Nacional, términos de calidad educativa ${ }^{102}$, competencias, flexibilidad curricular, internacionalización del currículo, entre otros, sin lograr esclarecer cuál es el pensamiento teórico educativo-pedagógico, que sustenta las reformas en cada universidad o el origen de los nuevos programas ${ }^{103}$.

En general, podríamos concluir quela educación y la pedagogía han transitado por diversos senderos y modelos ${ }^{104}$, según el período histórico de nuestras instituciones, formadoras de educadores en Colombia. En una primera instancia con Comenius que se preocupa por el arte de enseñar; la segunda, enmarca la pedagogía desde la filosofía; la tercera, la educación desde la concepción científica sustentada en el positivismo; la cuarta, se establecen las diferencias entre educación y pedagogía y se va estructurando la ciencia de la educación con otras disciplinas científicas ${ }^{105}$ y la quinta, las Ciencias de la Educación donde la interdisciplinariedad se trata de introducir en la sociedad del conocimiento.

En definitiva, la corriente epistemológica que sustenta las Ciencias de la Educación, para el siglo XXI, se establece de manera interdisciplinaria como ya lo señalaba Piaget, desde mediados del siglo XX. La ciencia que sustenta la educación ya no es la positivista ni se da el dilema de si la educación está centrada en el estudiante o en el profesor o en la tecnología (virtualidad). La nueva tendencia, consideramos, se enmarca en el rigor científico de las ciencias humanas, donde se enfoca la educación en el sujeto social histórico,

100 Ángel Díaz Barriga. ¿El enfoque de competencias en educación?, ¿Una alternativa o un disfraz de cambio? (México: Perfiles educativos, 2006); Ángel Díaz Barriga. La acreditación de programas (planes de estudio). Entre el formalismo y los procesos educativos. http://www. riseu.unam.mx (5 de agosto de 2010).

101 Nació en Poitiers, Francia, 15 de octubre de 1926 y muere en París, 25 de junio de 1984. Fue un filósofo e historiador francés.

102 La calidad se origina desde la empresa por el reconocimiento del producto. En la educación conlleva conceptos de: necesidad social; pertinencia, eficiencia, equidad. Lo relevante es que la UNESCO establece la calidad educativa desde la vinculación a una sociedad concreta. CEPAL, UNESCO, Educación y conocimiento, Eje de la transformación productiva con equidad (Santiago de Chile, 1992).

103 En los documentos maestros que hemos analizado en la Sala "Humanidades, Ciencias Sociales y Educación". CONACES en el período de octubre de 2012 a mayo de 2017, en su gran mayoría no se evidencia una producción teórica de los docentes ni una discusión, ni conceptualización propia sobre educación, Ciencias de la Educación y la pedagogía. En Colciencias se tienen clasificados 475 grupos de investigación en educación, pero desconocemos el impacto de los mismos en una teoría sobre pedagogía que esté impactando programas académicos y Facultades de Educación.

104 Carmen Amalia Camacho Sanabria. Texto de aula. Sociedad, pedagogía y educación (Bogotá: Universidad de la Salle, 2010), pp. 163203. Establece algunas preguntas para el desarrollo de la teoría pedagógica.

105 "Es la ciencia de educación, una ciencia autónoma, dentro de las ciencias del espíritu, que tiene una parte artística, una parte técnica, una parte teórica y una parte filosófica...Es multidisciplinaria", Lorenzo Luzuriaga, Op. cit. (1961), p. 12. 
mediada siempre en procesos de investigación educativa. La educación, por lo tanto, es multidisciplinar y la formación del educador en las facultades de ciencias de la educación, solo se puede establecer desde la construcción de sujetos críticos, con identidad y liderazgo social. Colombia, requiere de filósofos, como Guillermo Hoyos, que nos pongan a pensar en nuevos paradigmas, desde y para la realidad Latinoamericana y las Facultades de Educación, con los doctorados en Educación, deben aportarle al país la producción científica, con la que se sustentan los programas académicos de formación de docentes.

En conclusión, la legislación, enfoques educativos y modelos pedagógicos en la formación de educadores en Colombia, presentan una polémica más que se da entre lo disciplinar, lo pedagógico y el imaginario ${ }^{106}$ social de la función docente. Precisamente, este imaginario social sobre el educador es el que ha venido determinando unas políticas y legislación educativa en Colombia, en especial, y América Latina, en general, de tal manera que ese imaginario social sobre el educador, cambia según la región, y para el siglo XXI se arrastra con problemáticas no resueltas del siglo XX, tanto en lo legislativo, como en los contextos socio-culturales regionales.

Las grandes preguntas que se plantean son: 1) ¿Cuál es el educador que egresa como persona y profesional de las facultades de educación en Colombia? 2. ¿Las políticas públicas del Ministerio de Educación, que se cristalizan en los registros calificados y las acreditaciones de alta calidad, están incidiendo en los enfoques de la educación y modelos pedagógicos? 3 . ¿Las puntuales polémicas entre lo disciplinar y lo pedagógico presentan un ideal de educador?

\section{Aproximación a un Modelo Pedagógico}

Ubicándonos en la facultad de educación de la UPTC, que actualmente presenta un total de 35 programas, de los cuales 13 son de pregrado, 10 acreditados de alta calidad en el CNA, y 22 de postgrado. Con un total de 5996 estudiantes y 326 docentes, de los cuales 256 son de tiempo completo ${ }^{107}$. Además, posee 4 doctorados y un postdoctorado en Ciencias de la Educación. La Facultad se enmarca dentro del Plan de Desarrollo Institucional 20152026 ${ }^{108}$, que establece seis lineamientos: 1) Investigación e Innovación, 2) Formación y Docencia, 3) Extensión y Proyección Social, 4) Internacionalización e Interculturalidad, 5) Bienestar Universitario, 6) Modernización de la Gestión Administrativa y Financiera. Por su parte, la facultad de educación, bajo el plan estratégico, para el año 2017, ha priorizado sus actividades en la investigación, la internacionalización y las publicaciones.

\footnotetext{
106 Diana Elvira Soto Arango "Legislación e imaginarios sociales en el escalafón y los salarios de los educadores de primaria en Colombia. 1952-1994" Revista Historia de la Educación Latinoamericana, No. 21, Vol. 15 (2013): 229-262.

107 En los docentes se localizan 126 de TC de planta y 130 TC Ocasionales.

108 El Acuerdo 031 de 26 de mayo de 2015, aprueba el plan maestro de desarrollo Institucional 2015-2026 con 6 lineamientos.
} 
Partiendo del hecho que la facultad de educación, desde sus inicios, ha centrado su enfoque educativo en el humanismo ${ }^{109}$ católico, pero a partir de la Constitución de 1991, con la libertad religiosa, se estableció un cambio en el sector educativo público estatal en Colombia. Esta laicización se fue asimilando en las universidades desde las desigualdades de sus procesos históricos, locales y regionales y construyendo un nuevo enfoque con las vivencias colectivas propias, unidas a las corrientes pedagógicas externas ${ }^{110}$. Por lo anterior, desde finales del siglo XX, la facultad se dio a la tarea de la construcción de un humanismo crítico, sustentado en estrategias de varias escuelas y modelos pedagógicos. Ahora, en un proceso colectivo con estudiantes y profesores se replantea el educador que soñamos ${ }^{111}$, desde tres prospectivas: la primera, ubicándonos en el marco histórico de lo que ha representado la facultad y la universidad en el contexto nacional educativo, en el siglo $\mathrm{XX}$, y lo que se propone la institución con la normativa y plan de desarrollo a 2026; la segunda, desde la cotidianidad de los imaginarios colectivos, de identidades, sueños y utopías de educadores y educandos; y la tercera, ubicada en la responsabilidad social regional, nacional y latinoamericana.

Necesariamente, partimos de la misión de la Facultad que se identifica como una escuela de pensamiento pedagógico que, a través de la investigación, fundamenta la docencia, prestando un servicio social con excelencia, a la región, al país, a América y al mundo. De ahí que define su misión desde la formación integral de profesionales de la educación en todos los niveles, desde la calidad y pertinencia académicas, la idoneidad, la ética, la pedagogía, y la identidad profesional y personal.

Precisamente, el Consejo de la Facultad de Educación, el 22 de marzo de 2017, estableció que esta Facultad tiene "la responsabilidad de educar y formar seres humanos distintos entre sí y con necesidades y problemas sociales muy particulares". Y se estableció que "las humanidades significan una apertura al conjunto y a la diversidad de las expresiones culturales, religiosas y filosóficas de la humanidad"112. De esta manera, nuestro enfoque en la educación ${ }^{113}$ está acorde con lo indicado en el razonamiento y construcción colectiva de la Facultad ${ }^{114}$.

109 Ocampo conceptualiza el humanismo como el "conjunto de tendencias espirituales y filosóficas que tiene por objeto el desarrollo de las cualidades esenciales del hombre". Javier Ocampo López, Op. cit. (2001), p. 255.

110 Diana Elvira Soto Arango. "La universidad Latinoamericana en el siglo XXI" Revista Historia de la Educación Latinoamericana $\mathrm{N}^{\circ} 8$ (2006), p. 127.

111 Se sustenta en la investigación realizada por el grupo HISULA, sobre La Universidad Pedagógica y Tecnológica de Colombia. En los desafíos del Siglo XXI. Una prospectiva desde los estudiantes y Docentes. Tunja, UPTC, 2016, SGI. 1965: Proyecto Escenarios para la Prospectiva Universitaria de la UPTC. Contribuciones de la comunidad universitaria. Investigación de futuros. (Proyecto realizado entre HISULA y en alianza grupo Símiles. Tunja, UPTC, 2015. SGI 1302. Publicados resultados en Revista Historia de la Educación Latinoamericana. 2016.

112 Consejo de la Facultad de Educación del 22 de marzo de 2017, Acta 07, p. 6.

113 En la legislación colombiana se considera la educación como "un proceso de formación permanente, personal, cultural y social que se fundamentan en una concepción integral de la persona humana, de su dignidad, de sus derechos y de sus deberes"'. Ley 115 de 8 de febrero de 1994, art. 1.

114 Esta síntesis la asimilamos de filósofos y pedagogos clásicos y colombianos como Guillermo Hoyos, el Padre Borrero y la producción académica de docentes de la Facultad y sus pares académicos representada en las 7 revistas indexadas en Colciencias en A2. Véase otros trabajos de Diana Elvira Soto Arango, "El profesor universitario de América Latina. Hacia una responsabilidad ética-científicosocial" Revista Historia de la Educación Latinoamericana No 13 (2009): 166-188; Diana Elvira Soto Arango "La universidad 
Partiendo de este enfoque y en un intento de generar un espacio para el diálogo de saberes, teorías y conceptos, que sustentan el proceso educativo de los diferentes programas, que establecen miradas diversas en la formación del educador, nos aproximamos al modelo pedagógico que, como hemos indicado, se sustenta en el acto del conocimiento que está dado por la construcción colectiva, entre educador y educando, para tener como resultado uno nuevo, de manera individual.

El distintivo de este modelo pedagógico lo ubicamos en el compromiso de la formación de educadores con liderazgo, principios éticos, pensamiento crítico y autónomo, con identidad en el contexto histórico, social, multicultural del país y Latinoamérica. Ciudadanos que tengan la sensibilidad para que todo acto de conocimiento se oriente a la responsabilidad social, para lograr la anhelada cultura de paz en Colombia.

Nuestra aproximación a este modelo pedagógico la establecemos a través de la construcción de una tríada que, en primera instancia, instituimos en el acto del conocimiento que se va a construir, por una parte, desde el educador y por otra desde el educando. Además, ingresa en esta tríada la relación que se da entre educando y educador para la construcción del objeto. De manera global, se localiza los principios y valores que desde la integridad, la ética, valores socio-culturales y nivel de compromiso social, van a permear el objeto y la relación de educador y educando ${ }^{115}$.

En relación al primer aspecto de la identificación y selección del acto del conocimiento y en el cómo se aproxima a ese objeto, nuevo o no, para el educando, tiene relación directa con el currículo, los planes educativos, la visión y la misión de la universidad. Nos interesa conocer la persona que se quiere formar en el hoy, en los aspectos del saber y humanos en un contexto social, para poder proyectarla desde su pasado histórico al siglo XXI. De allí, la relevancia del paradigma de la formación del educador, que en nuestra Facultad está centrada en lograr ese equilibrio de teoría-práctica, mediado por la investigación y en el compromiso social con la región y el país. Pero ese deber ser, lo definen la institución y el educador al determinar, en cada momento, cuál es el acto del conocimiento. En general, expresaríamos que es el Estado-sociedad la que va a marcar el derrotero del proceso social, que desea para los individuos de su comunidad. Desde allí se marcan los referentes éticos culturales que se valoran como lo apropiado para los individuos, que van a pertenecer a esta sociedad y se establecen en cada momento histórico, unos objetos y formas de funcionamiento en esta sociedad en general y la particular, si nos referimos a la universidad.

De esta manera, el acto de conocimiento que se construye presenta valores y normas socio-culturales y del conocimiento científico, que se operacionaliza en las políticas del Estado y en la legislación vigente nacional e institucional. En

Latinoamericana en el siglo XXI” Revista Historia de la Educación Latinoamericana $\mathrm{N}^{\circ}$ 8, (2006), p. 130.

115 Diana Soto Arango, "Criterios comunes para el desarrollo de una educación universitaria global. Una propuesta latinoamericana”. En ¿Hacia dónde va la educación universitaria americana y europea? Colección Historia y prospectiva de la universidad latinoamericana, tomo II (São Paulo: UNINOVE, Universidad Pedagógica y Tecnológica de Colombia, RUDECOLOMBIA, (2006): $53-54$. 
nuestro caso, nos regimos por la Ley 30 de 1992 y en la formación de docentes por la Ley 115 de 1994. Además, ${ }^{116}$ para la formación de profesores se dio, en el año 2015 y 2016, una serie de Decretos y Resoluciones, ${ }^{117}$ que no tuvieron en cuenta las realidades educativas de un país, que no se transforma por una legislación sino por un trabajo colectivo con los docentes, que viven en el día a día, la realidad educativa en las instituciones escolares y universidades. Sin embargo, rescatamos el Decreto 2041 de 2016 que volvió la mirada hacia la investigación en la práctica pedagógica.

Pensamos que concurre no solo un vínculo sino múltiples, en la construcción del acto de conocimiento. Es así que el objeto del acto de conocimiento es intencional y está dado por la institución educativa, el Estado y la sociedad. Estas correspondencias se tornan complejas, si entendemos que en el Estado no solo existen las clásicas ramas del poder, sino también el conjunto sistémico de elementos que configuran la cultura política. Es decir, las mentalidades y los imaginarios colectivos, las prácticas de los sujetos, las formas de sociabilidad de los diversos grupos (civiles y militares, laicos y religiosos) y los torrentes de ideas que circulan por los variados medios, que desde hace tres siglos se renuevan para hacer proliferar textos, imágenes y voces ${ }^{118}$, en el campo de la educación en Colombia.

Por otra parte, la Facultad de Educación, en concreto, se apropia re-construye y visibiliza las políticas en la reglamentación de los currículos ${ }^{119}$, que forman a los educadores, pero esto no significa que los actos del conocimiento se repitan de manera similar, generación tras generación. Por el contrario, estos son cambiantes y continuamente se construyen nuevos modelos de comportamiento, que involucran lo antiguo, lo presente y la prospectiva del futuro y el educando lo construye de manera autónoma.

El segundo aspecto, referente a la relación que se da entre educando y educador para la construcción del acto del conocimiento, solo se concibe desde el diálogo que se establece entre educador-educando y el medio, sustentado en el paradigma de la pedagogía (poiesis-praxis) ${ }^{120}$. Esta pedagogía, necesariamente, se da a través de nuevas formas de intervención del educador ${ }^{121} \mathrm{y}$ del educando, mediante la reflexión.

Es necesario indicar que, la Ley 115 de 1994 estableció la conceptualización de educador, como: "el orientador en los establecimientos educativos, de un proceso de formación, enseñanza y aprendizaje de los educandos, acorde con las

116 Diana Soto Arango, "Periodos de reforma universitaria en Colombia de la colonia al siglo XXI" Revista Historia de la Educación Latinoamericana, $\mathrm{N}^{\circ} 22$, Vol. 16, (2014): 277-337.

117 Decretos 1075/ 2015 y 2450/2015 y la Resolución 02041/2016.

118 Proyecto de investigación "La Universidad en la formación de la nación colombiana. Siglos XVIII a XXI", presentado al Centro de investigación VENDIMIA por el Grupo de Investigación Historia y Prospectiva de la Universidad Latinoamericana- HISULA (Marco teórico, 2007), p. 6 -7.

119 Abraham Magendzo. Dilemas del currículo y la pedagogía. Analizando la reforma desde una perspectiva crítica (Santiago: LOM Ediciones, 2008), pp. 11.

120 Poiesis se refiere a la creatividad en los griegos. Heidegger la utiliza como iluminación.

121 Diana Soto Arango, "El profesor universitario de América Latina. Hacia una responsabilidad ética-científico-social" Revista Historia de la Educación Latinoamericana $\mathrm{N}^{\circ} 13$, (2009): 166-188. 
expectativas sociales, culturales, éticas y morales de la familia y la sociedad"122. Sin embargo, esta misma Ley aprobó una excepción para ejercer la docencia, donde se indica que: "en las áreas de la educación media y técnica para las cuales se demuestra carencia de personas licenciadas o escalafonadas con experiencia en el área, podrán ejercer la docencia los profesionales egresados de la educación superior en campos afines" ${ }^{\prime 23}$. Después de 23 años de estar aplicando esta norma, la brecha que se abrió es alta, porque los concursos docentes nacionales dan una prioridad al conocimiento disciplinar, donde las plazas son ocupadas por profesionales, diferentes a los formados en las Facultades de Educación.

Nosotros, al educador lo conceptualizamos como: "un actor social en unos espacios de poder local y nacional, que es especialista en la actividad docente y obra pedagógica"124. Quien establece la mediación en un diálogo con el educando a través de: integridad, ética, trasparencia, diálogo, comprensión, respeto, generosidad, solidaridad, confianza, buen carácter, pensamiento crítico, cooperación, equidad, entre otras.

En efecto, la preocupación central es la formación de este pedagogo, porque en él históricamente se ha centrado la esperanza, los ideales, la responsabilidad de lo que será el ciudadano del futuro cercano. Es allí, donde el referente teórico de las Ciencias de la Educación y en concreto de la pedagogía, actualmente tienen la palabra.

Es así, que consideramos que el acto de conocimiento es un proceso pedagógico de construcción de un objeto, en una realidad cambiante, que está mediado por el educador y el educando. Pero, para acceder a ese objeto, por parte del educador, consideramos que en la institución universitaria se debe orientar desde el pensamiento creativo, para conectar el conocimiento de la disciplina con el cómo se enseña, sin reducir el discurso a la instrumentalización, porque de hecho se reduce la principal cualidad del ser humano como es la creación ${ }^{125} \mathrm{y}$ el pensar utopías ${ }^{126}$, por las que sueña y batalla hasta hacerlas realidad. Se podría indicar que nada está construido, nadie tiene la última palabra, es una relación dialéctica, mediada por la ética y los valores socio-culturales, entre el educador y el educando.

El tercer elemento de la tríada es el educando, que la legislación colombiana conceptualiza como: "el centro del proceso educativo y debe participar activamente en su propia formación integral"127. Desde nuestros trabajos lo concebimos como la persona que está construyendo su conocimiento de manera autónoma, pero inmerso en un contexto socio-histórico-político-cultural. El educando establece una doble relación. Por una parte, con el educador con el

122 Ley 115 de 8 de febrero de 1994. Art.104. Publicado en el Diario oficial ํㅜ 41.214 del 8 de febrero de 1994.

123 Ley 115 de 8 de febrero de 1994. Art.108. Publicado en el Diario oficial No 41.214 del 8 de febrero de 1994.

124 Concepto del proyecto "Educadores Latinoamericanos". Cfr. Diana Elvira Soto Arango, La universidad en el período colonial (Tunja: Universidad Pedagógica y Tecnológica de Colombia, 2011), p. 19.

125 Joan-Carles Mèlich, Antropología simbólica y acción educativa (Barcelona: Paidós, 2004); Joan-Carles Mèlich, "La sabiduría de lo incierto. Sobre ética y educación desde un punto de vista literario", Educar No. 31 (2003): 33-45.

126 José Antonio Pérez Tapias, “Cambio de paradigma en el pensar utópico”, Diálogo filosófico No. 44 (1999): 206-209. (180-210).

127 Ley 115 de 8 de febrero de 1994. Art. 91. Publicado en el Diario oficial \# 41.214 del 8 de febrero de 1994. 
cual debe tener empatía, respeto, diálogo, confianza y por otra parte con el acto del conocimiento. Es allí donde desarrolla su pensamiento crítico, reflexivo, investigativo, interpreta la realidad y construye su identidad.

Cabe anotar que el educando para construir el acto del conocimiento parte de su experiencia y de la relación que tenga con el educador. Es así, que se hace necesario, para que ambos accedan, desde diferentes lugares y ópticas, al acto del conocimiento el establecer una relación psico-afectiva de armonía, tolerancia y respeto mutuo. De ahí que se construirá de manera individual y a su vez colectiva ese nuevo conocimiento.

En este sentido, el educando, de manera autónoma y desde su percepción individual, se acerca a ese "acto", lo observa, le hace preguntas, y lo asimila en ese proceso de construcción colectiva, que al final queda como un acto de conocimiento completamente individual. Esto es, precisamente, el final cognitivo-individual. Cada persona crea su concepto, diferente al del educador o su condiscípulo, que le acompañó en la construcción de su acto del conocimiento.

Sin entrar en las teorías de los clásicos, hasta la actualidad, sobre la construcción individual de la realidad, debemos, sin embargo, destacar lo indicado por Kant en el llamado que realiza a la sensibilidad, para la receptividad que el psiquismo posee y donde el entendimiento produce las representaciones. Lo anterior, le lleva a señalar que: "sin sensibilidad ningún objeto nos sería dado y, sin entendimiento, ninguno sería pensado. Los pensamientos sin contenido son vacíos; las intuiciones sin conceptos son ciegas" ${ }^{128}$. Pero, Kant nos lleva a una lógica más en la educación. No es solo la construcción de un objeto de conocimiento, porque de allí se deriva la relevancia que se le da a la educación cuando expresa que: "la naturaleza humana se desarrolle cada vez mejor mediante la educación y que esta pueda adquirir una forma adecuada para la humanidad. Esto nos abre la perspectiva de un futuro género humano más feliz" ${ }^{\prime 129}$. Consideramos que si este proceso del acto del conocimiento no lleva una empatía (educadoreducando) y un fin último de la felicidad del ser humano, no tiene razón de ser.

Pero es que esta preocupación por el educando se convierte en un hilo conductor, desde el siglo XVIII hasta el XXI. Asimismo, la relación entre educador y educando, para llegar al entendimiento con armonía, donde lo central sea esta felicidad del ser humano. En este sentido, quizá, otro clásico que nos da las luces para un modelo pedagógico lo encontremos en Pestalozzi, quien manifiesta la necesidad de crear los ambientes de aprendizaje con "las palabras amables y un sentimiento de amor verdadero, y el aspecto mismo benévolo y la expresión de la mirada." ${ }^{130}$. Precisamente, este es el gran desafío y desde esta perspectiva, como lo indica Fernando Sabater: "lo primordial es abrir el apetito cognoscitivo

128 Immanuel Kant, Crítica de la razón pura (Madrid, Editorial Gredos, 2014), p. 86.

129 Kant establece que el hombre es la única criatura que ha de ser educada. Entendiendo por educación los cuidados (sustento, manutención), la disciplina y la instrucción, juntamente con la educación Immanuel Kant. Pedagogía. Traducción de Lorenzo Luzuriaga y José Luis Pascual, (Madrid: Edit Akal, 1991), pp. 20, 29.

130 Johann Heinrich Pestalozzi, Cartas sobre educación infantil (Madrid: Editorial Tecnos, 1996), p. 124. 
del alumno, no agobiarlo ni impresionarlo... Pero sobre todo el profesor tiene que fomentar las pasiones intelectuales"131

Pero la tríada es englobada por unos principios y valores fundamentales que se imprimen desde el enfoque educativo. Es allí, donde ingresa la ética, que la concebimos como los valores socio-culturales y el nivel de compromiso social, que permean el acto de conocimiento y la relación de educador y educando en la institución educativa. La ética, como una disciplina racional, traza el conjunto de valores que llevan a establecer los principios de la moral pública. Esta reflexión nos lleva a plantear valores comunes para el nivel de compromiso social, que debe tener el proceso educativo en la formación de personas en la UPTC. Principios, como la integridad, solidaridad, equidad, confianza, trasparencia, justicia, diálogo, tolerancia, generosidad, respeto, inclusión, comprensión, libertad responsable, y justicia deben, entre otros, guiar ese acto del conocimiento en el tiempo y los espacios que se propician en la universidad, para que los educandos construyan de manera autónoma su forma de aprender, donde la ética y la integridad sean el sello de su formación.

En definitiva, el mapa conceptual que nos guía para el modelo pedagógico lo establecemos desde una realidad que asumimos desde Freire, como el "acto del conocimiento" y al cual llegan, desde orillas diferentes, el educador y el educando, quienes deben tener una relación de empatía para la construcción colectiva de ese "acto de conocimiento", que luego es asimilado de manera individual, creando uno nuevo, cuyo objeto final sea generar felicidad a estos seres humanos: educador y educando.

Finalmente se debe establecer la diferencia entre enfoque educativo, modelo pedagógico, currículo, didáctica ${ }^{132}$ y planes de estudio, siendo lo general, para la institución educativa los dos primeros y lo particular los otros tres conceptos, para cada programa académico.

De esta manera y siendo consecuentes, con el enfoque humanista crítico, consideramos que no puede prevalecer ningún aspecto en la triada que formulamos del acto del conocimiento, educando y educador, mediado por el principio de la responsabilidad social y hacia la felicidad del ser humano.

131 Fernando Sabater, El valor de educar (Madrid, Editorial Ariel, 1999), pp. 123, 126.

132 La didáctica con su pionero reconocido Juan Amos Comenio (1592-1670). 


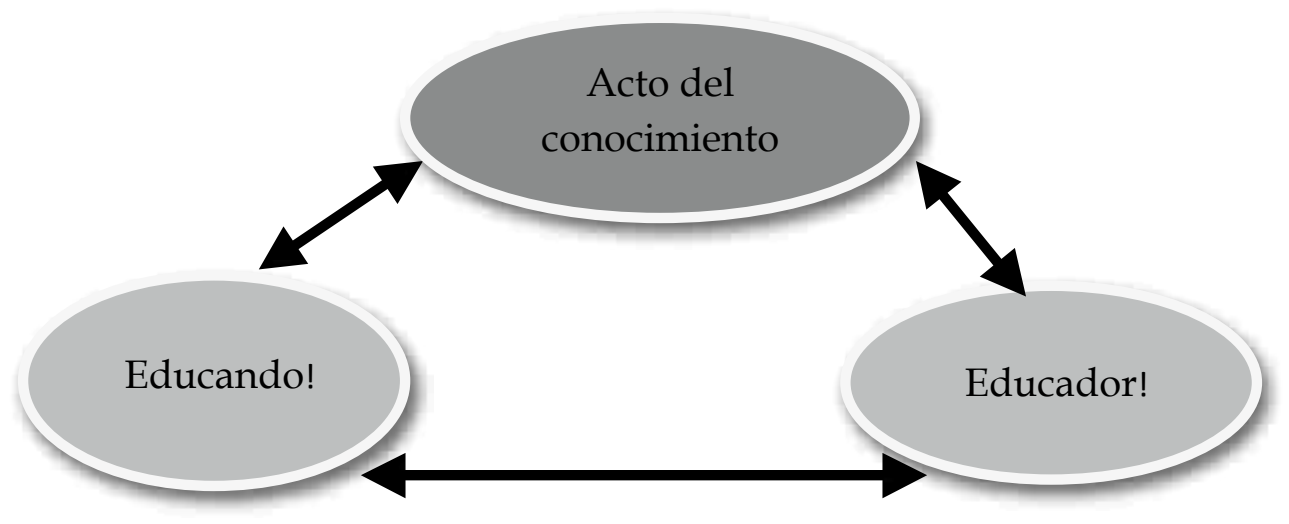

Fuente: elaboración autores.

\section{CONCLUSIÓN}

Acorde con la misión institucional y el enfoque educativo, se establece que esta Facultad centra la formación de los educadores y la práctica pedagógica bajo cuatro líneas de investigación, que marcan el derrotero del modelo pedagógico ${ }^{133}$, para permear los currículos y planes de estudio ${ }^{134}$ de los 35 programas académicos de la Facultad. Estas líneas marco se centran primero, en la Educación y formación de educadores. Segundo, Pedagogía, Currículo ${ }^{135}$ y Didáctica. Tercero, Humanidades, Artes y Ciencias Sociales. Cuarto, Educación en Ciencia, Tecnología y Ambiente. Siendo las dos primeras las que fundamentan el modelo pedagógico y las otras las que sustentan la formación disciplinar. Asimismo, producto del trabajo colectivo de docentes y estudiantes de los diferentes programas, con el análisis de los proyectos educativos, la encuesta con nueve preguntas, se establecen cinco componentes disciplinares que sustentan el modelo pedagógico, a saber: filosófico, epistemológico, antropológico, psicológico y sociológico.

Lo anterior se constituye en el sustento básico para que en nuestra concepción del acto del conocimiento, consideremos que solo puede darse a través y desde una perspectiva flexible, dialógica e incluyente, donde la Facultad proporciona los espacios, medios y estrategias, mediados por los valores éticos, para la construcción colectiva y a su vez individual de los saberes, que conllevan al proceso de la formación del docente, para ser ciudadanos en el

\footnotetext{
133 Este modelo se enmarca dentro de una institución educativa. Ley 115 de 1994, art. 10.

134 El Plan de estudios es "el esquema estructurado de las áreas obligatorias y fundamentales y de áreas optativas con sus respectivas asignaturas, que forman parte del currículo de los establecimientos educativos”. Ley 115 de 1994, art. 779.

135 Currículo es el conjunto de criterios, planes de estudio, programas, metodologías, y procesos que contribuyen a la formación integral y a la construcción de la identidad cultural nacional, regional y local, incluyendo también los recursos humanos, académicos y físicos para poner en práctica las políticas y llevar a cabo el proyecto educativo institucional. Ley 115 de 1994, art.76.
} 
mundo del conocimiento, con responsabilidad social sin olvidar su identidad latinoamericana, que le permite su pertenencia histórica. En especial, insistimos en nuestra identidad institucional, que solo lograremos por nuestros lazos de afectividad que se logren construir.

De esta manera, desde la mirada conceptual de la Educación y de la Pedagogía, para que se tenga la pertinencia y compromiso en la formación de los educadores, que requiere de los currículos abiertos, flexibles ${ }^{136}$, que van a organizar los procesos de formación en cuanto a los saberes y experiencias. En la Facultad de Educación están mediados por las citadas cuatro líneas de investigación, en orden descendente, el plan de estudios es uno de los componentes de la propuesta curricular que evidencia el conjunto de estrategias de enseñanza y de aprendizaje organizadas de manera intencional y con determinada disposición en cursos, contenidos, y experiencias de aprendizaje, desarrolladas a través de distintas metodologías, en concordancia con el campo del saber y las libertades de cátedra, enseñanza, aprendizaje e investigación. A cada uno de estos elementos constitutivos del plan de estudios, se les asigna un número de créditos académicos, con los cuales se busca que el trabajo del estudiante corresponda con sus posibilidades de dedicación y la naturaleza del programa. Es importante destacar que el crédito permite valorar el trabajo académico ${ }^{137}$ del estudiante, en términos de unidades de tiempo, que dedica para el logro de unos propósitos predefinidos de formación, y por su parte la flexibilidad ${ }^{138}$, hace referencia a estructuras y formas de relación abiertas, que comúnmente se encuentran en la organización de los aspectos académicos, pedagógicos, metodológicos, e incluso administrativos. En definitiva, los planes de estudio que presentan unos cursos y actividades académicas, deben ser consecuentes con los principios expresados en la concepción de Educación y Pedagogía y orientados hacia el currículo flexible y mediado por la investigación en la práctica pedagógica.

Finalmente, la Visión de la Facultad de Ciencias de la Educación se perfila como la primera institución formadora de docentes, mediante la construcción, aplicación y evaluación permanente de un Modelo de formación, basado en la investigación pedagógica, desde donde se realiza la docencia y la extensión, en un compromiso con la comunidad regional y nacional. De esta manera, se vislumbra a la Facultad de Ciencias de la Educación, comprometida con las instituciones gubernamentales en la formación integral del Normalista Superior, del Licenciado, del Especialista, del Magíster, del Doctor, del Postdoctor, para que cumplan las acciones de liderazgo y ostenten la capacidad para participar, desde los valores éticos, en la solución de problemas comunitarios, para el país

136 La flexibilidad junto con la interdisciplinariedad, la convergencia digital, ocasionan variaciones en la cultura de los sujetos en el proceso de desaprender para volver a aprender y "aprender para toda la vida". Soto Arango, Diana Elvira; Mesa Jiménez, Fredy Yesid; Caro, Edgar Orlando. "Convergencia digital en la universidad colombiana. Del siglo XX al XXI". Revista Historia de la Educación Latinoamericana. Vol. 14 No, 19, (2012).

137 Se estableció en Colombia mediante el Decreto 2566 de 9 octubre de 2003. Art. 18: Créditos académicos. Un crédito 48 horas.

138 Diana Elvira Soto Arango y Carlos Mosquera. La flexibilidad curricular en el registro calificado de Colombia. Bogotá, Propuesta presentada a la Sala Conceptual de Coordinadores de Consejo Nacional de Aseguramiento de la Calidad Superior. CONACES. del día 2 de octubre de 2013, p. 6. 
que soñamos, en la utopía de asimilar y aportar en los nuevos retos que nos plantea el siglo XXI.

En este contexto, ubicándonos desde la Facultad de Educación de la UPTC, en el año 2017, con la responsabilidad de formar educadores en los diferentes niveles educativos en Colombia y para esta generación ubicada en lo global, se tiene la doble responsabilidad de construir el acto del conocimiento bajo las prácticas de los valores y los sueños anhelados, que traen los educandos, con los posibles que desean poner en práctica los educadores y los que presenta la institución universitaria, en su enfoque educativo y modelo pedagógico. Pero, ante todo, este modelo pedagógico debe llevar ese sentir y generosidad, que convierte el ejercicio del desempeño del educador en parte de su proyecto de vida, con las emociones, los afectos y alegrías que conlleva la identidad de esta profesión. Es decir, es la actividad que como seres humanos realizamos en primera instancia, porque estamos identificados con nuestro quehacer profesional que nos agrada, produce y da felicidad y segundo, porque somos conscientes de nuestra responsabilidad social.

\section{FUENTES}

Legislación: Constitución Política de Colombia (1991); Ley 30 de 1992; Ley 115 de 1994; Decreto 916 del 2001; Decreto 2566 de 2003. Decreto 1001 del 2006. Ley 1188 del 2008. Decreto 1295 del 2010. Decreto 1279 de 2012 Ley 1075 de 2015; Resolución 2041 de 2016.

Archivos: Facultad de Educación y Fondo Posada de la Universidad Pedagógica y Tecnológica de Colombia.

Revistas: Revista Educación, 1933 y 1934. Revista Escuela Normal, 1870. Revista Historia de la Educación Latinoamericana.1998- 2017. Revista Colombiana de Educación, 1977.

Tesis Doctorado Ciencias de la Educación. CADE. Universidad Pedagógica y Tecnológica de Colombia, RUDECOLOMBIA, 2003- 2017.

\section{REFERENCIAS}

Bronislaw, Baczko. Los imaginarios sociales. Memorias y esperanzas colectivas. Buenos Aires, Ediciones nueva Visión, 1991. Primera versión París 1984.

Calvache López, José. "La escuela nueva y los conceptos básicos de la educación en el pensamiento de John Dewey. Una aproximación teórica", Revista Historia de la Educación Latinoamericana No. 5, (2003): 107, 110.

Camacho Sanabria, Carmen. Texto de aula. Sociedad, pedagogía y educación (Bogotá: Universidad de la Salle, 2010), pp. 163-203. 
Consejo Nacional de Educación Superior. CESU. “Construyendo una política pública de educación superior" Boletín del Consejo Nacional de Educación Superior Nº 1 (2015).

De Sousa Santos, Boaventura, Refundación del Estado en América Latina. Perspectivas desde una epistemología del Sur La Paz, Bolivia: Plural Editores, 2010.

Heinrich Pestalozzi, Johann. Cartas sobre educación infantil. Madrid: Editorial Tecnos, 1996.

Hernández García, José. “La influencia pedagógica del exilio republicano español: la edad de oro de la enseñanza en Colombia". Revista Latinoamérica No. 54 (2012) México.

Lawrence Stenhouse. Investigación y desarrollo del currículo. Madrid: Ediciones Morata, 1984.

Gagné, Robert. Las condiciones del aprendizaje. México: Editorial Interamericana, 1965.

Freire, Paulo. La Educación como práctica de la libertad. Buenos Aires, Siglo XXI Editores, 1969.

Freire, Paulo. Pedagogía de la indignación: cartas pedagógicas en un mundo revuelto. Buenos Aires: Siglo Veintiuno Editores, 2012.

Kant, Immanuel. Crítica de la razón pura. Madrid, Editorial Gredos, 2014.

Magendzo, Abraham. Dilemas del currículo y la pedagogía. Analizando la reforma desde una perspectiva crítica. Santiago: LOM Ediciones, 2008.

Mora García, José; Soto Arango, Diana y Lima Jardilino José. “La historia de la educación en América Latina: Contribución y aportes de la Sociedad de Historia de la Educación Latinoamericana SHELA (1994-2015)" Revista Historia da Educação No. 51, Vol. 21 (2017): 351- 375.

Nieto Caballero, Agustín. "Principios de la Escuela Nueva" Revista Historia de la Educación Latinoamericana No. 5 (2003): 141.

Pérez Tapias, José. “Cambio de paradigma en el pensar utópico", Diálogo filosófico $\mathrm{N}^{\circ} 44$ (1999): 206-209.

Piaget, Jean. Psicología Genética. Buenos Aires: EMECÉ Editores, 1973, primera edición. Traducido por Antonio Battro.

Puyana, Aura y Serrano, Mariana. Reforma o inercia en la universidad latinoamericana. La Universidad Nacional de Colombia y la Universidad Nacional Autónoma de México. Bogotá: Tercer Mundo, Universidad Nacional de Colombia e IEPRI, 2000.

Sabater, Fernando. El valor de educar. Madrid, Editorial Ariel, 1999.

Soto Arango, Diana; Bernal Villate, Sandra y otros. La independencia americana. Textos, enseñanza e imaginarios escolares en Colombia y España. Tunja, Universidad Pedagógica y Tecnológica de Colombia, 2017.

Soto Arango, Diana; Mesa Jiménez, Fredy y Caro, Orlando. “Convergencia Digital en la Universidad Colombiana" Revista Historia de la Educación Latinoamericana No. 19 (2012): 265-300.

Soto Arango, Diana. "Legislación e imaginarios sociales en el escalafón y los salarios de los educadores de primaria en Colombia. 1952-1994" Revista Historia de la Educación Latinoamericana, No. 21, Vol. 15 (2013): 229-262.

Soto Arango, Diana. "La universidad Latinoamericana en el siglo XXI" Revista Historia de la Educación Latinoamericana No. 8 (2006), p. 127. 
Soto Arango, Diana. “El profesor universitario de América Latina. Hacia una responsabilidad ética-científico-social" Revista Historia de la Educación Latinoamericana No. 13 (2009): 166-188

Soto Arango, Diana. "La universidad Latinoamericana en el siglo XXI" Revista Historia de la Educación Latinoamericana No. 8, (2006), p. 130.

Soto Arango, Diana. "Periodos de reforma universitaria en Colombia de la colonia al siglo XXI" Revista Historia de la Educación Latinoamericana, No. 22, Vol. 16, (2014): 277-337.

Soto Arango, Diana y Mosquera, Carlos. La flexibilidad curricular en el registro calificado de Colombia. Bogotá, Propuesta presentada a la Sala Conceptual de Coordinadores de Consejo Nacional de Aseguramiento de la Calidad Superior. CONACES. del día 2 de octubre de 2013.

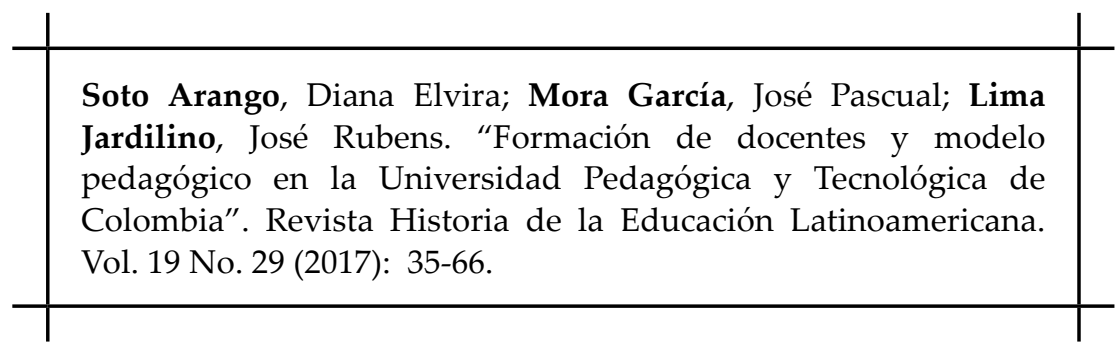

